\title{
Labor Market Heterogeneity and the Aggregate Matching Function*
}

\author{
Regis Barnichon \\ Andrew Figura \\ CREI, Universitat Pompeu Fabra and Barcelona GSE \\ Federal Reserve Board
}

September 2013

(First version: October 2010)

\begin{abstract}
The matching function - a key building block in models of labor market frictions-implies that the job finding rate depends only on labor market tightness. We estimate such a matching function and find that the relation, although remarkably stable over 1967-2007, broke down spectacularly after 2007. We argue that labor market heterogeneities are not fully captured by the standard matching function, but that a generalized matching function that explicitly takes into account worker heterogeneity and market segmentation is fully consistent with the behavior of the job finding rate. The standard matching function can break down when, as in the Great Recession, the average characteristics of the unemployed change too much, or when dispersion in labor market conditions -the extent to which some labor markets fare worse than others- increases too much.
\end{abstract}

JEL classifications: J6, E24, E32.

\footnotetext{
${ }^{*}$ We thank Jan Eeckhout, Bruce Fallick, Shigeru Fujita, Jordi Gali, Robert Hall, John Haltiwanger, Bart Hobijn, Rob Valletta, Thijs van Rens, William Wascher, Yanos Zylberberg and seminar participants at the 2012 AEA Annual Meetings, the 2012 CEPR European Summer Symposium in International Macroeconomics (ESSIM), the CREI-CEPR Conference "Understanding Jobless Recoveries", the Chicago Fed, the New York Fed, the Norges Bank, and the San Francisco Fed. We thank Peter Chen for excellent research assistance. The views expressed here do not necessarily reflect those of the Federal Reserve Board or the Federal Reserve System. Any errors are our own.
} 


\section{Introduction}

The search and matching model (Mortensen and Pissarides, 1994) has become the canonical framework to introduce equilibrium unemployment in macroeconomic models. One of its fundamental building blocks is the aggregate matching function that relates the flow of new hires to the stocks of vacancies and unemployment. Like the aggregate production function, the matching function is a convenient device that "partially captures a complex reality [...] with workers looking for the right job and firms looking for the right worker" (Blanchard and Diamond, 1989).

Standard specifications of the aggregate matching function imply that the aggregate job finding rate depends only on one aggregate variable: labor market tightness - the vacancyunemployment ratio-. We estimate a matching function tying the job finding rate to labor market tightness over 1967-2012, and we find that the relation, although remarkably stable over 1967-2007, broke down spectacularly after 2007: As of late 2012 (three years into the official recovery), the observed value of the job finding rate is 30 percent lower than implied by the behavior of the vacancy-unemployment ratio. In other words, a fundamental device in the macro-labor literature, the matching function, appears to have broken down.

Understanding the causes of the matching function breakdown is not only important from an academic point of view, but is also relevant for practitioners and policy makers concerned about the recent (and future) behavior of the unemployment and labor force participation rates. Using a stock-flow accounting framework, we quantify the magnitude of the matching function breakdown in units of unemployment and participation rates. As shown in Figure 1, the unexplained decline in the job finding rate corresponds to a $1 \frac{1}{2}$ percentage points higher unemployment rate since 2007 , as well as a $1 \frac{1}{2}$ percentage points lower participation rate. ${ }^{1}$ There is currently a lively debate about the causes of the dramatic decline in participation since 2007, and the breakdown of the matching function is an important, but so far little studied, aspect of that decline. ${ }^{2}$

Although the standard matching function is meant to capture "a trading technology between heterogeneous agents" (Pissarides 2000, p.4), this paper argues that labor market heterogeneities are not fully captured by the matching function. We construct a generalized matching function that explicitly allows for labor market segmentation and heterogeneity across workers, and that nests the standard matching function as a special case when the degree of hetero-

\footnotetext{
${ }^{1}$ Movements in the job finding rate have a mechanical effect on the participation rate, because of a composition effect: Unemployed workers are much more likely to leave the labor force than employed workers. By raising the number of unemployed workers relative to the number of employed workers, a lower job finding rate increases the number of individuals who leave the labor force, and the participation rate goes down.

${ }^{2}$ See, e.g., Aaronson et al. (2012), Van Zandweghe (2012), Erceg and Levin (2013) for recent work on the reasons for the decline in participation.
} 
geneity across workers and labor markets is constant. We find that the generalized matching function does a very good job at capturing movements in the job finding rate over 1976-2012, and we conclude that the matching function is a useful, and empirically successful, device to think about the functioning of the labor market. However, the standard matching function can break down, when the degree of heterogeneity in the labor market varies substantially, as was the case during the Great Recession.

We generalize the standard matching function by explicitly incorporating two dimensions of heterogeneity in the labor market. First, we incorporate worker heterogeneity by allowing for different levels of search efficiency across workers, i.e., we allow for the possibility that some individuals have a higher propensity to form a match than others. Second, we do not impose the existence of a unified labor market but instead allow the labor market to be segmented in submarkets, where each submarket is described by a matching technology.

According to this generalized matching function, the behavior of the aggregate job finding rate depends not only on aggregate labor market tightness, but also on aggregate matching efficiency -the ability of the labor market to match unemployed workers to jobs-. We show how aggregate matching efficiency can move over the cycle because of variations in the average characteristics of the labor market, and we highlight the role of two effects. The first one is a composition effect, due to the fact that the average search efficiency of the unemployment pool can vary over time. For instance, if composition changes, and a group with a lower than average search efficiency (such as long-term unemployed) becomes more represented among the unemployed, the average job finding probability will decline more than what the standard matching function would imply. The second effect is a dispersion effect, in which dispersion in labor market conditions, the fact that tight submarkets coexist with slack ones, drives down the aggregate job finding probability because of the concavity of the matching function. ${ }^{3}$ If dispersion increases, the average job finding probability will decline more than what the standard matching function would imply.

The standard matching function cannot capture these composition and dispersion effects, because it assumes a constant aggregate matching efficiency. In this framework, the standard matching function is an approximate description of the functioning of the labor market, but the approximation is only valid when the degree of heterogeneity in the labor market does not vary too much. As a result, the standard matching function can break down when the average characteristics of the unemployed change too much or when the dispersion in labor market conditions across submarkets changes too much.

\footnotetext{
${ }^{3}$ The effect of labor misallocation on matching efficiency in the context of the matching function is similar to the effect of capital misallocation on aggregate TFP in the context of the production function and emphasized in recent studies (e.g., Hsieh and Klenow, 2009).
} 
Estimating the generalized matching function requires data on worker characteristics as well as labor market characteristics, in particular, local labor market conditions. We use matched CPS micro data over 1976-2012 to control for worker characteristics. Controlling for local labor market conditions (i.e., labor market tightness at the segment level) is difficult, because there are no data on job openings at the local level over a long time sample. We propose a new method to infer local labor market tightness at a high level of disaggregation and over a long time series (1976-2012) by combining CPS micro data over 1976-2012 with the Conference Board online help-wanted ads data available since 2006.

We find that the generalized matching function does a very good job at explaining movements in the aggregate job finding rate over 1976-2012. Aggregate matching efficiency is procyclical, because both the composition effect and the dispersion effect are procyclical. First, in recessions, dispersion in labor market tightness across segments rises -some segments fare much worse than others- and aggregate matching efficiency declines leading to fewer matches than predicted by a standard matching function. ${ }^{4}$ Second, in recessions, composition changes and the average quality, or employability, of the unemployment pool worsens leading to fewer matches than predicted by a standard matching function. The two key individual characteristics responsible for the composition effect are reason of unemployment (e.g., job loser versus job leaver) -likely capturing unobserved heterogeneity across workers-, and unemployment duration - capturing unobserved heterogeneity across workers and/or the fact that workers' employability declines with the length of the unemployment spell (Kaitz, 1970). In recessions, the share of long-term unemployed and the share of job losers go up, leading to a decline in aggregate matching efficiency.

Turning to the exceptional behavior of the aggregate job finding rate since 2007, we find that both dispersion and composition -in particular, a large increase in the share of long-term unemployed- have driven down aggregate matching efficiency to exceptionally low levels, leading to a break-down of the standard matching function. Since 2009 -the end of the recession according to the NBER dating committee-, both the dispersion effect and the composition effect have remained at exceptional levels, keeping aggregate matching efficiency low and preventing unemployment from going down faster and participation from going up. This is in contrast to the early 80s, where both dispersion and composition mean-reverted quickly after the end of the recession.

While there is a large literature studying the aggregate matching function, ${ }^{5}$ this paper is

\footnotetext{
${ }^{4}$ Different mechanisms could explain the procyclicality of dispersion. For instance, changes in the location or nature of jobs can lead to more misallocation of jobs and workers in recessions and hence to a higher level of dispersion. Alternatively, different cyclical sensitivities to aggregate shocks across labor markets could also generate procyclical dispersion (Abraham and Katz, 1986).

${ }^{5}$ See, e.g., Pissarides (1986), Blanchard and Diamond (1989), Bleakley and Fuhrer (1997), the review of
} 
the first to propose, and estimate with micro data, a general framework to study how labor market segmentation and heterogeneity across workers and jobs affect the functioning of the labor market and the performance of the standard matching function.

Our concept of a generalized matching function encompasses two separate strands of the literature, a first one related to our composition effect, and a second one related to our dispersion effect.

A first strand of the literature has studied the individual determinants of unemployment duration (see Devine and Kiefer, 1991 for a review), and Baker (1992) uses micro data to study how changes in the average characteristics of the unemployment pool can affect the average unemployment exit rate (although without considerations for the performance of the matching function). However, because these studies were conducted without specific concern for the underlying matching technology, ${ }^{6}$ there was no consensus on how to capture the effect of worker characteristics or control for labor market conditions. ${ }^{7}$ In contrast, this paper incorporates worker heterogeneity and controls for labor market conditions in a manner fully consistent with the existence of matching technology. This approach allows us to clearly specify the conditions under which the standard matching function can (approximately) describe the functioning the labor market.

A second strand of the literature has focused on measuring the extent of mismatch in the labor market. This paper contributes to that literature by providing a dispersion measure -the variance of labor market tightness across labor market segments- that can be analytically related to aggregate matching efficiency and to the unemployment and participation rates. ${ }^{8}$ More recently, Sahin, Song, Topa, and Violante (2012) construct mismatch indices based on a theoretical model of mismatch. Sahin et al.'s mismatch measure and our dispersion measure are related, both relying ultimately on the concavity of the matching function. ${ }^{9}$ Different from Sahin et al. (2012), we focus on the performances of the aggregate matching function and on the simultaneous roles of the dispersion and composition effects. Moreover, while Sahin

Petrongolo and Pissarides (2001), Davis, Faberman and Haltiwanger (2010), Borowczyk-Martins, Jolivet, and Postel-Vinay (2012). Since the first draft of this paper, a number of papers have studied the behavior of the matching function during the last recession. See, e.g., Barlevy (2011), Veracierto (2011), Barnichon et al. (2012), Hobijn (2012), Ghayad and Dickens (2012), Sedlacek (2012).

${ }^{6}$ Lindeboom et al. (1994) and Petrongolo (2001) are two noteworthy exceptions (although with a different focus) that exploit the link between aggregate matching function and hazard rate specifications to estimate matching functions from micro data.

${ }^{7}$ For instance, Baker (1992) assumes that a worker's expected unemployment duration takes a logistic form, and the aggregate unemployment rate is added as an explanatory variable as a "cycle indicator" to control for aggregate labor market conditions.

${ }^{8}$ Previously, the literature had relied on a variety of dispersion measures (Padoa Schioppa, 1991, Layard, Nickell and Jackman, 2005) to capture the extent of misallocation of jobs and workers.

${ }^{9}$ In their framework, mismatch is defined as the distance between the observed allocation of unemployed workers across sectors and the optimal allocation that solves a planner's problem 
et al. (2012) probe mismatch using available vacancy data, which constrains their study to the last 5 to 10 years, our approach allows us to study the contribution of dispersion over the past 35 years. More generally, our paper contributes to the mismatch literature by providing a new method to estimate local labor market tightness from CPS micro data over a long sample period. ${ }^{10}$ This method opens the door to the possibility of measuring mismatch over a long time sample and help answer a key question for policy makers: whether mismatch is, or is not, a cyclical phenomenon, a question difficult to answer with only 5-10 years of data. Herz and van Rens (2011) propose an approach to study the sources and the cyclicality of mismatch over a long time sample. Although our approaches differ, our conclusions are consistent: both our dispersion measure and Herz et van Rens' (2011) mismatch measure appear to be strictly cyclical phenomena.

The next section estimates and evaluates the performances of a standard aggregate matching function. Section 3 presents an empirical framework to study how labor market heterogeneities affect matching efficiency. Section 4 uses micro data to estimate that framework, and Section 5 presents the results. Section 6 concludes.

\section{The standard matching function}

The matching function relates the flow of new hires to the stocks of vacancies and unemployment. In a continuous time framework, the flow of hires is typically modeled with a standard Cobb-Douglas matching function with constant returns to scale, and we can write

$$
m_{t}=\mu U_{t}^{\sigma} V_{t}^{1-\sigma}
$$

with $m_{t}$, the number of new hires at instant $t, U_{t}$ the number of unemployed, $V_{t}$ the number of vacancies, and $\mu$ a constant term. ${ }^{11}$

Since the job finding rate $f_{t}$ is the ratio of new hires to the stock of unemployed, we have $f_{t}=\frac{m_{t}}{U_{t}}$ so that

$$
f_{t}=\mu \theta_{t}^{1-\sigma}
$$

with $\theta=\frac{V}{U}$ the aggregate labor market tightness. We estimate the matching function in the log-linear form

$$
\ln f_{t}=(1-\sigma) \ln \theta_{t}+\ln \mu+\varepsilon_{t}
$$

\footnotetext{
${ }^{10}$ Relatedly, Hobijn (2012) proposes a method to measure the number of job openings at a unique level of disaggregation (374 industry-occupation combinations) over 2005-2011.

${ }^{11}$ The Cobb-Douglas matching function is used in almost all macroeconomic models with search and search and matching frictions (e.g., Pissarides, 2000). Allowing for non constant returns to scale or using a more general CES matching function $m_{t}=\mu\left[\sigma U_{t}^{\rho}+(1-\sigma) V_{t}^{\rho}\right]^{1 / \rho}$ gives very similar results.
} 
with $\ln \mu$ the intercept of the regression.

We measure the job finding rate $f_{t}$ from unemployment-employment transitions from the Current Population Survey (CPS) over 1976-2012 and from the worker flows data tabulated by Joe Ritter for the period 1968-1975. We use the composite help-wanted index presented in Barnichon (2010) as a proxy for vacancy posting. We use non-detrended quarterly data and estimate (3) over 1968-2007. Table 1 presents the results. Using OLS, the elasticity is estimated at 0.33 . Using lagged values of $v_{t}$ and $u_{t}$ as instruments gives similar results, and the elasticity is little changed at $0.34 .^{12}$

Figure 2 plots the empirical job finding rate, its fitted value, and the regression residual $\varepsilon_{t}$. While aggregate labor market tightness does a good job at capturing movements in the aggregate job finding rate up until 2007, a testimony of the success of the matching function, the residual shows a spectacular decline after 2007, implying that the observed job finding rate is much lower than predicted by the matching function. As of late 2012, the observed value of the job finding rate is 30 percent lower than implied by the level of the vacancy-unemployment ratio. $^{13}$

Using a stock-flow accounting framework (described in the Appendix), we can quantify the magnitude of the matching function break-down in units of unemployment and participation rates. The unexplained decline in the job finding rate corresponds to a $1 \frac{1}{2}$ percentage points higher unemployment rate since 2007 , as well as a $1 \frac{1}{2}$ percentage points lower participation rate (Figure 3). ${ }^{14}$

There is currently a lively debate about the causes of the decline in the level of participation since 2000 and in particular since $2007,{ }^{15}$ and the low level of the job finding rate is an important, but so far little studied, aspect of that decline. More generally, the apparent downward trend in matching efficiency since the early 2000 is remarkably correlated with the decline in the participation rate (Figure 1). While the cause of the decline in participation since the early 2000s is still an open question, Figure 1 indicates that the breakdown of the matching function is an important, but so far little studied, aspect of that decline.

Finally, note that even before 2007, the residual of the matching function displays a puzzling cyclical pattern; increasing in the later stages of expansions, peaking in the late stages of

\footnotetext{
${ }^{12}$ As argued by Borowczyk-Martins et al. (2013), OLS may suffer from an endogeneity bias because of agents' endogenous behavior.

${ }^{13}$ Elsby, Hobijn and Sahin (2010) report a similar finding using the unemployment outflow rate, and Davis, Faberman and Haltiwanger (2010) also report a dramatic decline in the vacancy yield using JOLTS data.

${ }^{14}$ Movements in the job finding rate have a mechanical effect on the participation rate, because of a composition effect: Unemployed workers are much more likely to leave the labor force than employed workers. By raising the number of unemployed workers relative to the number of employed workers, a lower job finding rate increases the number of individuals who leave the labor force, and the participation rate goes down.

${ }^{15}$ See, e.g., Aaronson et al. (2012), Van Zandweghe (2012), Erceg and Levin (2013).
} 
recessions or the early stages of recoveries, and declining thereafter.

\section{A generalized matching function with labor market hetero- geneities}

Although the matching function is meant to capture "a trading technology between heterogeneous agents" (Pissarides 2000, p.4), we now argue that labor market heterogeneities, in particular heterogeneities across individuals and labor markets, are not fully captured by the matching function but are important to understand fluctuations in the job finding rate (and thus unemployment and participation).

We construct a generalized matching function that explicitly incorporates labor market heterogeneities and that nests the standard matching function as a special case when the degree of heterogeneity in the labor market remains constant. Specifically, we generalize the aggregate matching function in two dimensions. First, we explicitly incorporate worker heterogeneity by allowing for different levels of search efficiency across workers. Intuitively, we allow for the possibility that some individuals have a higher propensity to form a match than others, i.e., a higher search efficiency. Second, we do not impose the existence of a unified labor market but instead allow the labor market to be segmented in submarkets, where each submarket is described by a matching technology.

In this framework, the behavior of the aggregate job finding rate depends not only on the behavior of aggregate labor market tightness, but also on the behavior of aggregate matching efficiency, -the ability of the labor market to match unemployed workers to jobs--. In contrast, the standard matching function takes aggregate matching efficiency as a constant.

We show how aggregate matching efficiency can move over the cycle because of variations in the average characteristics of the labor market, and we highlight the role of two effects: a composition effect, coming from the composition of the unemployment pool, and a dispersion effect, coming from the amount of dispersion in labor market conditions. The former arises if the characteristics of job seekers change over time, making job finding more or less likely, while the latter is caused by the concavity of the matching function and arises if tight labor markets coexist with slack labor markets.

\subsection{A generalized matching function}

We first present our derivation of a generalized matching function.

There are $I$ labor market segments and $J$ worker types. The labor market segment $i \in$ $\{1, . ., I\}$ of individual type $j \in\{1, . ., J\}$ can then be thought as the labor market in which 
individual $j$ is most likely to look for work and to find a job. A labor market segment can defined by its geographic location, industry group and occupation group. Each labor market segment $i$ has a matching technology which depends on $V_{i t}$, the number of job openings in segment $i, U_{i t}$, the number of unemployed in segment $i$, and $\mu_{i}$, the constant matching efficiency of segment $i$. Heterogeneity in matching efficiency captures the idea that some occupations or locations have a higher rate of matching than others. ${ }^{16}$ The matching technology is described by a CRS Cobb-Douglas matching function.

Each worker type $j$ in segment $i$ is characterized by his search efficiency $s_{j i t}$, which depends on characteristics that make him more or less likely to form a match. We do not take a stand on the mechanism behind the different search efficiencies, but simply allow for the presence of heterogeneity in that dimension. Without loss of generality, we normalize average search efficiency to 1 by appropriately rescaling the $\mu_{i}$ s (the matching efficiency levels of the segments).

The number of new hires in segment $i, m_{i t}$, is thus given by

$$
m_{i t}=\mu_{i} V_{i t}^{1-\sigma}\left(s_{i t} U_{i t}\right)^{\sigma}
$$

with $s_{i t}$, the average search efficiency in segment $i$, given by

$$
s_{i t} \equiv \sum_{j=1}^{J} \frac{U_{j i t}}{U_{i t}} s_{j i t}
$$

with $U_{j i t}$ the number of unemployed workers of type $j$ in segment $i$ at time $t$ so that $U_{i t}=$ $\sum_{j} U_{j i t}$

The total number of matches in the economy, $m_{t} \equiv \sum_{i=1}^{I} m_{i t}$, is then given by a generalized matching function

$$
m_{t}=\mu_{t} V_{t}^{1-\sigma} U_{t}^{\sigma}
$$

with aggregate matching efficiency given by

$$
\mu_{t}=\sum_{i=1}^{I} \frac{U_{i t}}{U_{t}} \mu_{i} s_{i t}^{\sigma}\left(\frac{\theta_{i t}}{\theta_{t}}\right)^{1-\sigma}
$$

with $V_{t} \equiv \sum_{i=1}^{I} V_{i t}$ and $U_{t} \equiv \sum_{i=1}^{I} U_{i t}$ the total number of vacancies and unemployed in the

\footnotetext{
${ }^{16}$ For instance, hiring for high-skill occupations may be more time-consuming than hiring for low-skill occupations. As a result, low skill occupations may display a higher number of new matches per unit of time (for a given number of job seekers and job openings), i.e., a higher matching efficiency.
} 
economy, $\theta_{i t} \equiv \frac{V_{i t}}{U_{i t}}$ the labor market tightness in segment $i$ and $\theta_{t} \equiv \frac{V_{t}}{U_{t}}$ the aggregate labor market tightness.

Expression (7) generalizes the standard matching function by explicitly allowing (i) for worker heterogeneity, and (ii) segmentation in the labor market. Thanks to (7), we can link movements in aggregate matching efficiency to observable characteristics of the labor market, and movements in aggregate matching efficiency $\mu_{t}$ can thus be decomposed into a composition effect and a dispersion effect.

\subsection{A decomposition of aggregate matching efficiency}

With some manipulation of (7) left for the Appendix, the aggregate job finding rate $f_{t}=\frac{m_{t}}{U_{t}}$, can be approximated as

$$
\begin{aligned}
\ln f_{t} & =\ln \mu_{t}+(1-\sigma) \ln \theta_{t} \\
\text { with } \mu_{t} & \simeq \mu_{0}(1+\underbrace{\mu_{t}^{s}+\mu_{t}^{m}}_{\text {Composition }}-\underbrace{\frac{\sigma(1-\sigma)}{2} \operatorname{Var}\left(\frac{\theta_{i t}}{\theta_{t}}\right)}_{\text {Dispersion }})
\end{aligned}
$$

to a second-order in the degree of heterogeneity across worker characteristics and across labor market tightnesses, with $\mu_{0}$ the average matching efficiency level across segments.

This decomposition of the aggregate job finding rate highlights how, with worker heterogeneity and concavity in the matching technology, changes in composition and dispersion can lead to movements in aggregate matching efficiency $\mu_{t}$, i.e., movements in the aggregate job finding rate that are not captured by an aggregate function that depends only on labor market tightness. In other words, for small variations in the degree of labor market heterogeneity, the terms on the right hand-side of (9) move little and we have $\mu_{t} \simeq \mu,{ }^{17}$ and the generalized matching function $-m_{t}=\mu_{t} V_{t}^{1-\sigma} U_{t}^{\sigma}$ - can be approximated by a standard matching function $-m_{t}=\mu V_{t}^{1-\sigma} U_{t}^{\sigma-}$.

Looking into the components of (9), the first term in (9) captures the aggregate job finding rate (8) $\mu_{0} \theta_{t}^{1-\sigma}$ absent worker heterogeneity and absent dispersion in labor market tightness across segments.

The second term in $(9), \mu_{t}^{s}+\mu_{t}^{m}$, describes the composition effect coming from

1. $\mu_{t}^{s}=\sigma \sum_{i, j} \frac{U_{j i t}}{U_{t}}\left(s_{j i t}-1\right)$ capturing the effect of changes in the composition of the unemployment pool. For instance, if the share of a group (e.g. long term unemployed)

\footnotetext{
${ }^{17}$ We have $\mu=\mu_{0} E\left(1+\mu_{t}^{s}+\mu_{t}^{m}-\frac{\sigma(1-\sigma)}{2} \operatorname{Var}\left(\frac{\theta_{i t}}{\theta_{t}}\right)\right)$.
} 
with a lower than average job finding probability increases in recessions, then the average job finding probability will decline without any change in individuals' job finding probabilities.

2. $\mu_{t}^{m}=\sum_{i} \frac{U_{i t}}{U_{t}}\left(\frac{\mu_{i}}{\mu_{0}}-1\right)$ capturing the effect of changes in the distribution of the unemployed across segments with different average matching efficiency. For instance, if a higher fraction of the unemployed becomes concentrated in a segment with higher matching efficiency, the average job finding probability will increase even if the aggregate numbers of vacancy and unemployed remain constant.

The third term in (9) captures the effect of dispersion in labor market conditions on the average job finding probability. Intuitively, dispersion in labor market tightness across segments negatively affects the average job finding rate, because the segment-level job finding rate $f_{i t}=\frac{m_{i t}}{U_{i t}}$ is a concave function of labor market tightness $\theta_{i t}$ (because the matching function $m_{i t}=\mu_{i} V_{i t}^{1-\sigma}\left(s_{i t} U_{i t}\right)^{\sigma}$ is a concave function of $U_{i t}$ and $\left.V_{i t}\right)$. As a result, if some segments (such as health care) display a relatively tight labor market and some segments (such as manufacturing) display a slack labor market, the average job finding probability will be lower than in an economy where labor market tightness is identical across segments. ${ }^{18}$

Going back to the performance of the standard matching function, equation (9) highlights how the standard matching function can break-down, when $\mu_{t}$ deviates too much from its average value $\mu$ because (i) the composition of the unemployment pool changes too much ( $\mu_{t}^{s}$ and/or $\mu_{t}^{m}$ move too much) and/or (ii) the dispersion in labor market conditions across segments, $\operatorname{Var}\left(\frac{\theta_{i t}}{\theta_{t}}\right)$, changes too much.

\section{Estimation procedure}

In this section, we present our approach to bring the generalized matching function to the data. We use matched monthly data from the Current Population Survey (CPS) covering January 1976 to December 2012 to estimate the Unemployment-Employment transition probability $F_{j i t}$ for an individual $j$ in labor market segment $i$ at time $t$.

\footnotetext{
${ }^{18}$ Note that the dispersion effect is proportional to the variance of relative labor market tightness, so that one can readily estimate the effect of dispersion on the unemployment rate by looking at the dispersion in labor market conditions. The literature on mismatch has used various measures to quantify the effect of misallocation on the unemployment rate (Padoa Schioppa, 1991). While all these measures capture the extent of dispersion across labor markets, the measure we propose has an important advantage over these other measures: It can be directly related to aggregate matching efficiency and, thus, through its effect on the job finding rate, to the unemployment and participation rates.
} 
Given the matching technology (4), the job finding rate of an individual type $j$ in segment $i$ at time $t, f_{j i t}$, is given by

$$
\begin{aligned}
f_{j i t} & =\frac{s_{j i t}}{s_{i t} U_{i t}} m_{i t} \\
& =\mu_{i} \frac{s_{j i t}}{s_{i t}} s_{i t}^{\sigma} \theta_{i t}^{1-\sigma}
\end{aligned}
$$

and the job finding probability

$$
F_{j i t}=1-e^{-\mu_{i} \frac{s_{j i t}}{s_{i t}} s_{i t}^{\sigma} \theta_{i t}^{1-\sigma}} .
$$

A major limitation when estimating (10) is the absence of data on job openings, and hence labor market tightness, at the segment level over a long time sample. ${ }^{19}$ In particular, the Help Wanted OnLine (HWOL) dataset provided by the Conference Board provides information on the number of job openings by geographic location, occupation and/or industry at a very disaggregated level, allowing researchers to measure labor market tightness at a high level of disaggregation (as recently used by Sahin et al., 2012). However, the sample period covered by HWOL starts only in 2006 and is too short for our purpose.

To overcome this data limitation, we propose a two-stage estimation procedure that overcomes the need for job openings data over a long time sample. In the first stage, we use the fact that each individual is atomistic in his labor market segment, ${ }^{20}$ so that we can use the segment-specific average job finding rate (measurable from CPS micro data) to control for market tightness at the segment level. This first stage allows us to measure the effect of worker characteristics -the composition effect- while controlling for local labor market conditions. In the second stage, we propose a method, combining the HWOL data with the CPS micro data, to estimate the elasticity of the matching function $\sigma$ (and the segment-specific matching efficiency $\mu_{i}$ ), and recover time series of local labor market tightness over 1976-2012.

We define a labor market segment by its geographic location and occupation group, and we disaggregate the labor market into 45 segments defined by 9 geographic locations and 5 occupation groups. Specifically, we use the nine US Census Divisions and the five high-level SOC occupation groups Professional, Services, Sales and Office, Construction, and Production. ${ }^{21}$

\footnotetext{
${ }^{19}$ In the US, the two public data sources with vacancy posting data are the Job Openings and Labor Turnover Survey (JOLTS) and the Help-Wanted OnLine series from the Conference Board. The JOLTS measure of job openings can be disaggregated into about 15 industry groups, but the series only start in 2000 .

${ }^{20}$ This approach is thus valid as long as the labor market segment is not too tightly defined.

${ }^{21}$ At this level of disaggregation, an individual is clearly atomistic. The 9 Census divisions are New England, Middle Atlantic, East North Central, West North Central, South Atlantic, East South Central, West South Central, Mountain and Pacific. The five SOC high-level occupation groups are: Professional (Management, Business, Science and Arts), Services (Personal services), Sales (Sales and Office), Construction and Maintenance, and Production and Transportation. Only about $2 \%$ of unemployed are missing occupation information.
} 


\section{Stage 1. Estimating the effect of workers' characteristics}

In the first stage, we estimate the effect of worker characteristics on an individual job finding rate while controlling for local labor market conditions.

To capture the effect of individual characteristics on search efficiency, we posit that $s_{j i t}$, the search efficiency of worker type $j$ at time $t$, is given by

$$
s_{j i t}=e^{\beta X_{j i t}}
$$

with $X_{j i t}=\left[1, x_{j i t}^{1}, . ., x_{j i t}^{K}\right]$ a vector of worker characteristics (detailed below) for type $j$ in segment $i$ at time $t$.

To estimate (10) without data on local market tightness $\theta_{i t}$, we note that, given (4), the average job finding rate in segment $i$ is

$$
f_{i t} \equiv \frac{m_{i t}}{U_{i t}}=\mu_{i} s_{i t}^{\sigma} \theta_{i t}^{1-\sigma}
$$

so that we can estimate the vector $\beta$-capturing the effect of individual specific characteristics on job finding probabilities- by estimating

$$
\begin{aligned}
F_{j i t} & =1-e^{-\frac{s_{j i t}}{s_{i t}} f_{i t}} \\
& =1-e^{-f_{i t} e^{\beta\left(X_{j i t}-X_{i t}\right)}}
\end{aligned}
$$

by maximum likelihood. ${ }^{22}$

We use three main types of information from the CPS to capture worker characteristics: demographics, reason for unemployment and duration of unemployment. ${ }^{23}$

Demographic information includes the age, sex and education level of the unemployed individual. We use 10 bins of 5 years to capture the effect of age on the job finding probability: Less than 20, 20-25,..., 55-60 and over 65 .

The CPS distinguishes between 5 main reasons for unemployment: permanent layoff, temporary layoff, new labor force entrant, reentering the labor force, and quit job. We use dummy variables for each reason. Reason for unemployment likely captures unobserved heterogeneity across individuals.

The CPS records the duration (in weeks) of individuals' current spells of unemployment.

\footnotetext{
${ }^{22}$ We restrict the estimation to pre-2008 data so that any changes in matching efficiency post 2007 do not affect our coefficient estimates. We discuss in the appendix the effect of including post-2008 data on our results.

${ }^{23}$ We also experimented with education level and race/ethnicity but found that these characteristics play little role in the cyclicality of matching efficiency, consistent with the findings of Baker (1992). We thus omitted these characteristics for clarity of exposition. We also include a set of monthly dummies to control for seasonality in job finding probabilities.
} 
Prior research (e.g., Kaitz 1970, Machin and Manning 1999) found that the job finding probability declines with duration, and we include unemployment duration as an explanatory variable. To capture the effect of duration, we use 10 bins of equal size (in terms of number of unemployed). In section 6 , we discuss the possible mechanisms behind the effect of duration.

In 1994, a major redesign of the CPS survey was implemented and introduced breaks in many important variables, such as reason for unemployment and duration of unemployment (Polivka and Miller, 1998). To control for these breaks, we estimate separate coefficients for the pre and post redesign periods.

\section{Stage 2. Measuring local labor market tightness and dispersion}

We still have two parameters to estimate: $\sigma$, the elasticity of the matching function, and $\mu_{i}$ the segment-specific matching efficiency. Moreover, in order to decompose matching efficiency and quantify the effect of dispersion on matching efficiency, we need data on local labor market tightness over a long time series. We now present a method that allows us to estimate $\sigma$ and $\mu_{i}$, and recover time series of local labor market tightness over 1976-2012.

The general idea is as follows: Once $\sigma$ is known, one can construct measures of local tightness from segment-specific average job finding rates. But once local tightness is known, we can estimate $\sigma$ from an aggregate matching function regression (similar to (3)) that explicitly takes into account the cyclical behavior (time-varying nature) of aggregate matching efficiency. After constructing sets of local market tightness measures for different values of $\sigma$, we find the $\sigma$ that best fit the behavior of aggregate job finding rate over 1976-2007.

Specifically, our approach proceeds in two steps. Note that in all this procedure, we take $\beta$, estimated in stage 1 , as given so that search efficiency, whether $s_{j i t}$ or $s_{i t}$, is known and taken as given.

- Step 1: We consider a grid over $[0,1]$ of possible values of $\sigma$, and for each value of $\sigma$ on this grid, we do two things: (i) estimate the $\mu_{i}$ s and (ii) construct series of local labor market tightness, the $\theta_{i t} \mathrm{~s}$.

To first estimate the $\mu_{i} \mathrm{~s}$, we use Conference Board HWOL job openings data to measure $\theta_{i t}$ over 2006-2007. ${ }^{24}$ Taking as given $\beta$ (estimated in the first stage) and $\sigma$, we estimate $\mu_{i}$ directly from (10) i.e., we estimate

$$
F_{j i t}=1-e^{-\frac{s_{j i t}}{s_{i t}} s_{i t}^{\sigma} \mu_{i} \theta_{i t}^{1-\sigma}}
$$

\footnotetext{
${ }^{24}$ Although HWOL data are available after 2007, we restrict our time sample to 2006-2007 to avoid using data from a period with unusual movements in aggregate matching efficiency. The 2006-2007 period is a period before the dramatic decline in matching efficiency, which allows us to estimate the $\mu_{i}$ s without biasing our results in favor of explaining the behavior of the job finding rate after 2007.
} 
by maximum likelihood. Note that $\frac{s_{j i t}}{s_{i t}} s_{i t}^{\sigma}$ is known in this stage, so that $\mu_{i}$ is the only free parameter.

Second, given $\mu_{i}$, we construct measures of local tightness from segment-specific average job finding rates by rearranging (11):

$$
\theta_{i t}=\left(\frac{f_{i t}}{\mu_{i} s_{i t}^{\sigma}}\right)^{\frac{1}{1-\sigma}} .
$$

- Step 2: In Step 1, we constructed two functions of $\sigma: \mu_{i}(\sigma)$ and $\theta_{i t}(\sigma)$. Using our generalized matching function (7), the aggregate job finding rate can then be written as

$$
\begin{aligned}
\ln f_{t} & =(1-\sigma) \ln \theta_{t}+\ln \left(\sum_{i=1}^{I} \frac{U_{i t}}{U_{t}} \mu_{i}(\sigma) s_{i t}^{\sigma}\left(\frac{\theta_{i t}(\sigma)}{\theta_{t}}\right)^{1-\sigma}\right) \\
& \equiv g(t, \sigma)
\end{aligned}
$$

The right-hand side of $(15), g(t, \sigma)$, is a function of $\sigma$, and we do a grid search over $[0,1]$ to find the $\sigma$ that minimizes the sum of squared differences between $\ln f_{t}$ and $g(t, \sigma){ }^{25}$ In essence, equation (15) generalizes the standard estimation of the elasticity of the matching function (regression (3) from Section 2) by taking into account the fact that the composition and dispersion effects can be cyclical and thus influence the value of $\sigma$. If, for instance, the composition or dispersion effect is procyclical (as is the case empirically), the standard matching function regression (3) will estimate $1-\sigma$ with an upward bias.

\section{$5 \quad$ Estimation results}

In this section, we present the results of our estimation and then analyze the behavior of the aggregate job finding rate since 1976 through the lens of our generalized matching function.

\subsection{Coefficient estimates}

Column (3) of Table 1 reports the results of our two-stage estimation procedure which explicitly takes into account movements in $\mu_{t}$ when estimating $1-\sigma$. At 0.18 , the elasticity is substantially

\footnotetext{
${ }^{25}$ In order not to bias our results in favor of explaining the behavior of the job finding rate since 2008, we only use data over 1976-2007 when estimating (15). The grid covers [0,1] in increments of 0.01 . The standard error is computed by Monte Carlo methods. Specifically, we sample a series $\varepsilon_{t}$ from the empirical distribution of the residuals $\ln f_{t}-g(t, \sigma)$, and we generate a new series $g(t, \sigma)+\varepsilon_{t}$ to which we apply our procedure and estimate a new value for $\sigma$. We repeat this exercise 1000 times. The standard error is then the standard deviation of these estimated $\sigma$ across all draws.
} 
lower than when using only aggregate labor market tightness as an explanatory variable. This indicates that the effect of labor market heterogeneities is on average procyclical, and that failing to control for heterogeneity biases estimates of the aggregate matching function elasticity upward.

Figure 4 presents the coefficients for the determinants of search efficiency, expressed in units of job finding rate for ease of comparison. ${ }^{26}$ The most important individual characteristic is unemployment duration. Search efficiency (i.e., the propensity to form a match) is decreasing in unemployment duration, consistent with previous findings on the existence of duration dependence (e.g., Kaitz 1970, Machin and Manning 1999, Shimer 2008, Kroft, Lange and Notowidiglo 2013). ${ }^{27}$

We find that the effect of duration on an individual's employment probability is large: for instance, an individual unemployed for six months is $50 \%$ less likely to find a job than an individual who just entered the unemployment pool. This estimate, based on workers' actual job finding rates, is remarkably similar to Kroft et al.'s (2013) result based on field experiment data on employers' callback rate. Moreover, consistent with Kroft et al. (2013), we find that workers' search efficiency drops sharply over the first 6 months of the unemployment spell and then stabilizes. We return to this finding in Section 7 where we discuss the possible mechanisms behind duration dependence.

The second most important characteristic is reason for unemployment. The estimates reveal that it is more difficult for permanent job losers and entrants to the labor force to find employment. New entrants fare worse than reentrants. Not surprisingly, workers on temporary layoff are the most likely to find a job, i.e., have the highest search efficiency.

Turning to demographics, the coefficients on the age variables indicate that search efficiency decreases with age. Quantitatively, a 60 -year old individual is $10 \%$ less likely to find a job than a 20-year old individual. The coefficient on the male dummy indicates that males are slightly more likely to find jobs than females.

Finally, more educated workers have higher search efficiency: a college graduate is $8 \%$ more likely to find a job than a high-school dropout.

\footnotetext{
${ }^{26}$ Figure 4 presents the coefficients estimated over 1994-2007. Recall that because of a break in 1994, we allowed for a break in the coefficients in 1994. The coefficients estimated over 1976-1993 (available upon request) are very similar.

${ }^{27} \mathrm{~A}$ contribution to that literature is that we estimate the strength of the duration dependence phenomenon after controlling for worker characteristics as well as local labor market conditions, in a manner fully consistent with the matching function framework.
} 


\subsection{Accounting for movements in the aggregate job finding rate}

Using our estimated coefficients, we now evaluate whether our generalized matching function can account for movements in the aggregate job finding rate. Figure 5 plots the movements in the job finding rate unexplained by the generalized matching function -the difference $\ln f_{t}-\ln \left(\mu_{t} \theta_{t}^{1-\sigma}\right)$ with $\mu_{t}$ given by (7)- along with the movements in the job finding rate unexplained by the standard matching function -the residual from regression $(3), \ln f_{t}-\ln \left(\mu \theta_{t}^{1-\sigma}\right)$, estimated in Section 2.

While the standard matching function has failed spectacularly since the beginning of the last recession, a generalized matching function, estimated with data prior to 2008, does a very good job at explaining the dramatic and prolonged decline in the job finding rate since 2008 . Even before the last recession, the generalized matching function substantially improves the fit of the data, reducing by more than $50 \%$ the volatility of the (already small) errors of the standard matching function. Calculating the coefficient of determination for both models over 1976-2012, we find that $\mathrm{R}^{2}$ increases from 0.78 using the standard matching function to 0.88 using the generalized matching function.

Recall that the standard matching function $-m_{t}=\mu V_{t}^{1-\sigma} U_{t}^{\sigma}$ - approximates the generalized matching function $-m_{t}=\mu_{t} V_{t}^{1-\sigma} U_{t}^{\sigma}$ - for small variations in labor market heterogeneities so that $\mu_{t} \simeq \mu$. Given the success of the generalized matching function at accounting for movements in the aggregate job finding rate, our findings point to an important conclusion: the concept of a matching technology provides a good framework to think about the functioning of the labor market. However, during extraordinary times (such as the Great Recession), labor market heterogeneities can vary substantially and assuming the existence of an aggregate matching function with constant matching efficiency $\left(\mu_{t} \simeq \mu\right)$ is not a valid approximation anymore.

\section{Aggregate matching efficiency and the break-down of the matching function}

In this section, we analyze the cyclical properties of aggregate matching efficiency, $\mu_{t}$, and its components, and we discuss the reasons for the matching function break-down after 2007.

\subsection{Aggregate matching efficiency over the cycle}

We first discuss the cyclical properties of $\mu_{t}$, the movements in aggregate matching efficiency implied by the generalized matching function given the observed movements in labor market 
heterogeneities. Figure 6 plots $\mu_{t}$ and its two components: the composition effect and the dispersion effect.

First, we can see from Figure 6 that composition and dispersion contribute roughly equally to movements in matching efficiency $\mu_{t}$ over the business cycle.

Second, dispersion appears to be mainly a pro-cyclical phenomenon -rising during recessions and abating during expansions (Figure 7)-. This is a new result, especially interesting in the context of the recent literature on mismatch. Indeed, dispersion is a concept very closely related to mismatch (Sahin et al., 2012), and a key question for policy makers and practitioners is whether mismatch is, or is not, a cyclical phenomenon, a question that has proven very difficult to answer with the time period covered by available data. Our results suggest that mismatch may be, after all, a mainly cyclical phenomenon. ${ }^{28}$

Third, the composition effect is procyclical. In recessions, the average quality, or employability, of the unemployment pool worsens leading to fewer matches than predicted by a standard matching function that takes only aggregate labor market tightness as argument. We explore the procyclicality of the composition effect in more details in the next section.

\subsection{The composition effect over the cycle}

In order to better understand how the composition of the unemployment pool affects $\mu_{t}$, we isolate the contributions of the different characteristics behind the composition effect. We find that the two key characteristics responsible for the composition effect are unemployment duration and reason of unemployment. In recessions, the share of long-term unemployed and the share of job losers go up, leading to a decline in aggregate matching efficiency.

Figure 8 graphs the contributions of individual characteristics $\mu_{t}^{s}$-unemployment duration, reason for unemployment, demographics (grouping together the contributions of age, sex and education)-, and the contribution of $\mu_{t}^{m}$ capturing the effect of changes in the distribution of the unemployed across segments with different average matching efficiency. The sum of these four components equal the contribution of the composition effect to $\mu_{t}$.

Unemployment duration accounts for a large fraction of the composition effect, a perhaps not surprising result given the strength of duration dependence, and duration depresses matching efficiency in the aftermaths of recessions. Reason for unemployment also lowers matching efficiency in recessions. This happens because recessions coincide with sharp increases in the fraction of permanent job losers (Figure 9), i.e., individuals with lower propensity to find a job, which worsens the employability of the unemployment pool. ${ }^{29}$

\footnotetext{
${ }^{28}$ This observation is in line with Hertz and van Rens (2011) finding (based on a different methodology) that mismatch is mainly cyclical.

${ }^{29}$ Note also that reason for unemployment tends to lift the job finding rate in recessions. This pattern owes
} 
Interestingly, unemployment duration and reason for unemployment generate some inertia in the behavior of $\mu_{t}$ and thus in the behavior of the aggregate job finding rate. By definition, unemployment duration is an inertial variable, and average unemployment duration lags the cycle. As a result, the component of $\mu_{t}^{s}$ driven by duration also lags the cycle; peaking at the end of expansions and bottoming a few years into the recovery. Similarly, the fraction of permanent job losers in the unemployment pool is a persistent variable. Permanent job losers have a low search efficiency (Figure 4), and many years of expansion are necessary to bring their share back to pre-recession levels (Figure 9).

Other characteristics play only a marginal role. Demographic characteristics have little effect on the cyclical behavior of aggregate matching efficiency, in line with Baker (1992), ${ }^{30}$ and changes in the distribution of the unemployed across segments $\left(\mu_{t}^{m}\right)$ have virtually no effect.

\subsection{The break-down of the matching function after 2007}

We now turn to the behavior of $\mu_{t}$ after 2007 and to the resulting break-down of the standard matching function.

As shown in Figure 6, both composition and dispersion drove down aggregate matching efficiency to exceptionally low levels, leading to a break-down of the standard matching function. Moreover, since 2009 -the end of the recession according to the NBER-, both dispersion and composition have remained at exceptional levels, keeping aggregate matching efficiency low and preventing unemployment from going down faster and participation from going up. Note also the very large contribution of duration during the recent recession (Figure 8). As average duration reached record highs (Figure 9), the average search efficiency of the unemployment pool deteriorated substantially, and, as a result, the aggregate job finding rate declined a lot more than implied by a standard matching function (where $\mu_{t}$ is assumed constant).

It is interesting to contrast the recent large recession with the large recession of the early 80s. While dispersion reached high levels in both recessions (Figure 7), the composition effect was much stronger in the 2008-2009 recession than it was in the 1980-1982 recession. ${ }^{31}$ This is

to an increasing share of temporary job losers during recessions (especially before 1985, Figure 4). At the onset of recessions, bursts of temporary layoffs lift the job finding rate because job losers on temporary layoffs have a higher search efficiency than average. This was especially the case in the 70s, and probably explains the sharp increases in the residual of the standard matching function regression during the 1970 and 1974 recessions (Figure 2).

${ }^{30}$ Demographics generated a downward trend in average search efficiency over the sample period, because the labor force got older (search efficiency declines with age, Figure 4) and because the share of women in the labor force increased (women have lower search efficiency than men, Figure 4).

${ }^{31}$ Note also that, compared to $1980, \mu_{t}$ entered 2008 at a much lower level, because both duration and the fraction of permanent job losers were not back to their pre-2001 level when the recession started. 
due to two effects (i) a much larger increase in the share of long-term unemployed over 20082009 than over 1980-1982, and (ii) opposite contributions of reason for unemployment. In the 1980-1982 recession, reason for unemployment raised aggregate matching efficiency, because of a sharp increase in the share of workers on temporary layoffs in the unemployment pool (Figures 8 and 9). In contrast, in the recent recession, the fraction of workers on temporary layoffs went down (firms rely less on temporary layoffs than in the early 80s), while the fraction of workers on permanent layoffs went up, which lowered aggregate matching efficiency.

One last interesting difference between the 1980-1982 and 2008-2009 recessions is the behavior of aggregate matching efficiency into the recovery. Since 2009, both dispersion and composition have remained at exceptional levels, keeping aggregate matching efficiency low and preventing unemployment from going down faster. This is in contrast to the early 80s, where both dispersion and composition mean-reverted quickly after the end of the recession (Figure 6 and 7 ).

\section{Discussion: the contribution of unemployment duration to the break-down of the matching function}

We found that the dramatic increase in unemployment duration after 2007 played an important role in the break-down of the matching function. ${ }^{32}$ In this section, we discuss the possible economic mechanisms behind the effect of unemployment duration on search efficiency, and we discuss the corresponding economic interpretation of the role of duration in the break-down of the matching function.

\subsection{Mechanisms behind duration dependence}

Theoretically, duration dependence can arise through two channels. First, the "accumulation" of unemployment duration could have a causal effect on workers' search efficiency and job finding probability. For instance, prolonged unemployment may lower individuals' skills relative to other job seekers, making them less desirable to employers (e.g., Pissarides, 1992), or it may reduce their contacts in job finding networks, making it harder to find employment. This mechanism is typically referred to as "true" duration dependence. Second, duration dependence could arise out of a dynamic selection process driven by unobserved worker heterogeneity: workers with high job finding probability (i.e., high search efficiency) leave unemployment faster than those with low search efficiency, thereby generating a negative correlation between dura-

\footnotetext{
${ }^{32}$ In the Appendix, we explore the robustness of this result to one important critique -that duration dependence may be time-varying, leading us to possibly overestimate the contribution of duration-.
} 
tion and job finding rates (Salant, 1977). This mechanism is typically referred to as "spurious" duration dependence. ${ }^{33}$

\subsection{An economic interpretation of the matching function break-down}

We now discuss the possible economic interpretation of the role of duration in the break-down of the matching function. Naturally, the interpretation depends on the mechanism behind duration dependence.

A true duration dependence mechanism would imply that the aggregate job finding rate dropped more than implied by the standard matching function because of the severity of the recession: as workers faced more difficulty in finding a job and stayed unemployed longer than in a mild recession, they lost their human capital in greater proportion, making them less employable and further depressing the aggregate job finding rate. This mechanism points towards a non-linear effect of recessions on the job finding rate: the more severe the recession, the longer workers stay unemployed, the poorer their employment prospects become, and thus the lower aggregate matching efficiency can fall (implying both higher unemployment and lower participation). In that case, the break-down of the standard matching function would simply a by-product of the severity of the recession.

Alternatively, a spurious duration dependence mechanism based on unobserved heterogeneity would imply that the aggregate job finding rate dropped more than implied by the standard matching function, because the 2008-2009 recession saw an exceptional increase in the number of unemployed workers with very poor employment prospects. This could be due to some technical change, such as job polarization -which affects unemployed workers harder during downturns (Jaimovich and Siu, 2013)-, that rendered a category of the population less employable. In that case, the break-down of the standard matching function would be the by-product of some technical change that made a category of the population less employable.

\footnotetext{
${ }^{33}$ While discriminating between these two channels is outside the scope of this paper, our evidence points towards some role for unobserved heterogeneity, in line with the recent findings of Kroft et al. (2013). First, the intensity of the decline in workers' search efficiency over the first months of unemployment (Figure 4) suggests that gradual loss of skill (i.e., true duration dependence) is unlikely to be the sole factor that accounts for duration dependence. This points towards a dynamic selection process driven by unobserved worker characteristics. Second, if workers' unobserved characteristics were behind the exceptional decline in matching efficiency since 2008, we should expect the residual from the generalized matching function regression (Figure 5) to (i) drop quickly at the onset of the recession as workers with (unobserved) low search efficiency become unemployed (and lower aggregate search efficiency more than $\mu_{t}$ would predict given observable characteristics) and, (ii) rise back to zero later in the recession as the unemployment duration of the low search efficiency types increases, signaling the presence of low search efficiency types (and allowing $\mu_{t}$ to capture the low level of aggregate search efficiency). Looking at Figure 5, this seems to be what happened, suggesting again a role for unobserved heterogeneity.
} 


\section{Conclusion}

The matching function -a key building block in the macro-labor literature- implies that the job finding rate depends only on labor market tightness. We estimate such a matching function and find that the relation, although remarkably stable over 1967-2007, broke down spectacularly after 2007. The magnitude of the break-down is large: it represents an increase in unemployment of about $1 \frac{1}{2}$ percentage points since 2007 , and a decrease in participation of about $1 \frac{1}{2}$ percentage points.

Although the matching function is meant to capture a trading technology between heterogeneous agents, we argue that heterogeneities across individuals and labor markets are not fully captured by the matching function but are key to understand fluctuations in the job finding rate (and thus unemployment and participation). We construct a generalized matching function that explicitly incorporates labor market heterogeneities and nests the standard matching function as a special case when the degree of heterogeneity in the labor market remains constant. In a generalized matching function framework, the behavior of the aggregate job finding rate depends not only on aggregate labor market tightness, but also on aggregate matching efficiency, -the ability of the labor market to match unemployed workers to jobs-- We show how aggregate matching efficiency can move through a composition effect, due to changes in the composition of the unemployment pool, and through a dispersion effect, in which dispersion in labor market conditions -the extent to which some labor markets fare worse than othersdrives down aggregate matching efficiency because of the concavity of the matching function.

We find that the generalized matching function does a very good job at capturing movements in the job finding rate since 1976, and we conclude that the concept of a matching technology provides a good framework to think about the functioning of the labor market. However, by not explicitly incorporating important dimensions of labor market heterogeneity, the standard matching function can apparently break down, when the degree of heterogeneity in the labor market varies substantially as in the Great Recession. Since 2007, the composition of the unemployment pool changed noticeably with an unprecedented increase in the share of long-term unemployed, and dispersion across segment rose substantially above its average level.

An implication of our results is that ignoring heterogeneity across workers and labor markets (as typically assumed in search and matching models, e.g., Pissarides, 2000) may yield an incomplete depiction of unemployment fluctuations. As such, explicitly incorporating heterogeneity across agents and modeling mobility decisions across segmented labor markets are important research projects. ${ }^{34}$

\footnotetext{
${ }^{34}$ For recent work in this direction, see Alvarez and Shimer (2011), Birchenall (2011), Carrillo-Tudela and
} 


\section{References}

[1] Aaronson, Daniel, Jonathan Davis, and Luojia Hu. "Explaining the Decline in the U.S. Labor Force Participation Rate." FRB Chicago, Chicago Fed Letter 296, 2012.

[2] Abraham, K. and L. Katz. "Cyclical Unemployment: Sectoral Shifts or Aggregate Disturbances?," Journal of Political Economy, Vol. 94, No. 3, pp. 507-522, 1986.

[3] Alvarez F. and R. Shimer "Search and Rest Unemployment," Econometrica, 79(1): 75$122,2011$.

[4] Baker, M. "Unemployment Duration: Compositional Effects and Cyclical Variability," American Economic Review, 1992.

[5] Barlevy, G. "Evaluating the Role of Labor Market Mismatch in Rising Unemployment," Federal Reserve Bank of Chicago, Economic Perspectives, Vol.35, Third Quarter, 2011.

[6] Barnichon, R. "Building a composite Help-Wanted index," Economics Letters, 2010.

[7] Barnichon, R., M. Elsby, B. Hobijn, A. Sahin. "Which Industries are Shifting the Beveridge Curve?," Monthly Labor Review, June, 2012.

[8] Birchenall, J. "A Competitive Theory of Mismatch," Working Paper, 2011.

[9] Blanchard O. and P. Diamond. "The Beveridge Curve," Brookings Paper on Economic Activity, 1:1-60, 1989.

[10] Bleakley H. and J. Fuhrer. Shifts in the Beveridge Curve, Job Matching, and Labor Market Dynamics," New England Economic Review, 1997.

[11] Borowczyk-Martins, D., G. Jolivet, and F. Postel-Vinay (2012). "Accounting For Endogeneity in Matching Function Estimation," Review of Economic Dynamics, 16, 440-51, 2013.

[12] Carrillo-Tudela, C. and L. Visscher. "Unemployment and Endogenous Reallocation over the Business Cycle," Wrking Paper, 2011.

[13] Davis, S., J. Faberman and J. Haltiwanger. "The Establishment-Level Behavior of Vacancies and Hiring," NBER Working Paper, 2010.

[14] Devine, T and N. Kiefer Empirical Labor Economics: The Search Approach, Oxford University Press 1991.

Visscher (2011), and Merkl and Van Rens (2011). 
[15] Elsby, M., B. Hobijn and A. Sahin. "The Labor Market in the Great Recession," Brookings Papers on Economic Activity, 1-48, 2010.

[16] Erceg, C. and A. Levin. "Labor Force Participation and Monetary Policy in the Wake of the Great Recession," Working Paper 2013.

[17] Ghayad R. and W. Dickens "What Can We Learn by Disaggregating the UnemploymentVacancy Relationship?", Public Policy Briefs No. 12-3, Federal Reserve Bank of Boston

[18] Herz, B. and T. van Rens. "Structural Unemployment," mimeo, 2011.

[19] Hsieh, C. and P. Klenow. "Misallocation and Manufacturing TFP in China and India," Quarterly Journal of Economics, 124, 1403-1448, 2009.

[20] Jaimovich, N. and H. Siu. "The Trend is the Cycle: Job Polarization and Jobless Recoveries," Working Paper, 2012.

[21] Layard R., S. Nickell, and R. Jackman. Unemployment: Macroeconomic Performance and the Labour Market, 2nd Edition, Oxford University Press, 2005.

[22] Kaitz H. "Analyzing the Length of Spells of Unemployment," Monthly Labor Review, 93(11):10-20, 1970.

[23] Kroft, K., M. Notowidigdo and F. Lange. "Duration Dependence and Labor Market Conditions: Evidence from a Field Experiment," Working Paper, 2013.

[24] Lindeboom, M., J. van Ours and R, Gusta. "Matching Employers and Workers: An Empirical Analysis on the Effectiveness of Search," Oxford Economic Papers 46: 45-67, 1994.

[25] Machin, Stephen, and Alan Manning. The Causes and Consequences of Long Term Unemployment in Europe. In Handbook of Labor Economics Vol. 3, ed Orley Ashenfelter and David Card, 3085-3139.Elsevier: Amsterdam, 1999.

[26] Merkl, C and T. van Rens. "Selective Hiring and Welfare Analysis in Labor Market Models," Working Paper, 2012.

[27] Mortensen, D and C. Pissarides. "Job Creation and Job Destruction in the Theory of Unemployment," Review of Economic Studies, 61, 397-415, 1994.

[28] Padoa Schioppa, F. Mismatch and Labor Mobility, Cambridge, Cambridge University Press, 1991. 
[29] Petrongolo, Barbara, "Reemployment Probabilities and Returns to Matching," Journal of Labor Economics, University of Chicago Press, vol. 19(3), pages 716-41, 2001.

[30] Petrongolo, B. and C. Pissarides. "Looking into the black box: A survey of the matching function," Journal of Economic Literature, 39: 390-431, 2001.

[31] Pissarides, C. "Unemployment and Vacancies in Britain," Economic Policy, 500-40, 1986.

[32] Pissarides, C. Loss of Skills during Unemployment and the Persistence of Employment Shocks," The Quarterly Journal of Economics, 107(4): 1371-91, 1992.

[33] Pissarides, C. Equilibrium Unemployment Theory, 2nd ed, MIT Press, 2000.

[34] Polivka, A. and S. Miller. "The CPS After the Redesign: Refocusing the Economic Lens." in Labor Statistics and Measurement Issues, edited by John Haltiwanger, Marilyn Manser, and Robert Topel. University of Chicago Press, 1998

[35] Sahin A., J. Song, G. Topa, and G. Violante. "Mismatch in the Labor Market: Evidence from the US," mimeo, 2012.

[36] Salant, S. "Search Theory and Duration Data: A Theory of Sorts," Quarterly Journal of Economics, 91(1): 39-57, 1977.

[37] Sedlacek, P. "Match Efficiency and the Cyclical Behavior of Job Finding Rates," mimeo, 2011.

[38] Shimer, R. "Reassessing the Ins and Outs of Unemployment," Review of Economic Dynamics, vol. 15(2), pages 127-148, April, 2012.

[39] Shimer, R. "The Probability of Finding a Job," American Economic Review (Papers and Proceedings), 98(2): 268-273, 2008.

[40] Van Zandweghe, W. 2012. "Interpreting the Recent Decline in Labor Force Participation." Economic Review, Federal Reserve Bank of Kansas City, 5-34.

[41] Veracierto. "Worker Flows and Matching Efficiency," Federal Reserve Bank of Chicago, Economic Perspectives, Vol. 35, Fourth Quarter, 2011. 


\section{Appendix}

\section{Expressing the matching function residual in units of unemployment and participation}

To express the residual $\varepsilon_{t}$ of the standard matching function regression

$$
\ln f_{t}=(1-\sigma) \ln \theta_{t}+\ln \mu+\varepsilon_{t}
$$

in units of unemployment and participation rate, we use the concept of steady-state unemployment and steady-state labor force participation, which closely approximate the actual unemployment and participation rates in the US (Shimer, 2012). The steady-state rates are the rates consistent with the underlying labor market flows (such as the flows from Unemployment to Employment) and provide us with accounting identities that allow us to quantify the effect of movements in the flows on the resulting stocks.

In what follows, for clarity of exposition, the job finding rate of the main text, $f_{t}$, will be denoted $\lambda_{t}^{U E}$. Specifically, workers can transit between the three labor market states employment (E), unemployment (U) and inactivity (I). Letting $\lambda_{i t}^{A B}$ denote the hazard rate of transiting from state $A \in\{E, U, I\}$ to state $B \in\{E, U, I\}$, unemployment, employment and inactivity will satisfy the system of differential equations

$$
\left\{\begin{array}{c}
\dot{U}_{t}=\lambda_{t}^{E U} E_{t}+\lambda_{t}^{I U} I_{t}-\left(\lambda_{t}^{U E}+\lambda_{t}^{U I}\right) U_{t} \\
\dot{E}_{t}=\lambda_{t}^{U E} U_{t}+\lambda_{t}^{I E} I_{t}-\left(\lambda_{t}^{E U}+\lambda_{t}^{E I}\right) E_{t} \\
\dot{I}_{t}=\lambda_{t}^{E I} E_{t}+\lambda_{t}^{U I} U_{t}-\left(\lambda_{t}^{I E}+\lambda_{t}^{I U}\right) I_{t}
\end{array}\right.
$$

In the U.S., the magnitudes of the hazard rates are such that the half-life of a deviation of unemployment from its steady state value is about one to two months (Shimer, 2012). As a result, at a quarterly frequency, the unemployment rate $u_{t}=\frac{U_{t}}{L F_{t}}$ is very well approximated by its steady-state value $u_{t}^{s s}$ so that we can use the accounting identity

$$
u_{t} \simeq u_{t}^{s s} \equiv \frac{\lambda_{t}^{E U}+\lambda_{t}^{E I} \frac{\lambda_{t}^{I U}}{\lambda_{t}^{I E}+\lambda_{t}^{I U}}}{\lambda_{t}^{E U}+\lambda_{t}^{E I} \frac{\lambda_{t}^{I U}}{\lambda_{t}^{I E}+\lambda_{t}^{I U}}+\lambda_{t}^{U E}+\lambda_{t}^{U I} \frac{\lambda_{t}^{I E}}{\lambda_{t}^{I E}+\lambda_{t}^{I U}}}
$$

Linearizing (18) around the mean of the job finding rate $\lambda_{t}^{U E}$, we get that the effect of movements in $\varepsilon_{t}$ on the unemployment rate are given by

$$
d u_{t}^{\varepsilon}=\beta^{U E} \lambda^{U E} \varepsilon_{t}
$$


with $\lambda^{U E}$ the mean of the job finding rate and $\beta^{U E}$ the coefficient of the Taylor expansion with respect to $\lambda_{t}^{U E}$.

A similar reasoning works with the labor force participation rate

$$
l_{t} \simeq l_{t}^{s s} \equiv \frac{U_{t}+E_{t}}{U_{t}+E_{t}+I_{t}}=g\left(\left\{\lambda^{A B}\right\}\right)
$$

and

$$
d l_{t}^{\varepsilon}=\gamma^{U E} \lambda^{U E} \varepsilon_{t}
$$

with $\gamma^{U E}$ the coefficient of the Taylor expansion with respect to $\lambda_{t}^{U E}$.

\section{A decomposition of movements in aggregate matching efficiency}

Recall that aggregate matching efficiency is given by

$$
\mu_{t}=\sum_{i=1}^{I} \frac{U_{i t}}{U_{t}} \mu_{i} s_{i t}^{\sigma}\left(\frac{\theta_{i t}}{\theta_{t}}\right)^{1-\sigma}
$$

with $s_{i t} \equiv \sum_{j=1}^{J} \frac{U_{j i t}}{U_{i t}} s_{j i t}$ the average search efficiency in segment $i, V_{t} \equiv \sum_{i=1}^{I} V_{i t}$ and $U_{t} \equiv$ $\sum_{i=1}^{I} U_{i t}$ the total number of vacancies and unemployed in the economy, $\theta_{i t} \equiv \frac{V_{i t}}{U_{i t}}$ the labor market tightness in segment $i$ and $\theta_{t} \equiv \frac{V_{t}}{U_{t}}$ the aggregate labor market tightness.

Without loss of generality, we normalize average search efficiency to 1 , so that $s_{0} \equiv$ $\frac{1}{T} \sum_{t=1}^{T} \sum_{i, j} \frac{U_{i j t}}{U_{t}} s_{i j t}=1$ by appropriately rescaling the $\mu_{i} \mathrm{~s}$.

Denote $\mu_{0}$ the average matching efficiency level across segments with $\mu_{0} \equiv \frac{1}{T} \sum_{t, i} \frac{U_{i t}}{U_{t}} \mu_{i}$.

Taylor expanding (19) with respect to $s_{i j t}$ around $1, \mu_{i}$ around $\mu_{0}$ and $\theta_{i t}$ around $\theta_{t}$ to a second-order, the aggregate matching efficiency can be written

$$
\begin{aligned}
\ln f_{t} & =\ln \mu_{t}+(1-\sigma) \ln \theta_{t} \\
\text { with } \mu_{t} & \simeq \mu_{0}(1+\underbrace{\mu_{t}^{s}+\mu_{t}^{m}}_{\text {Composition }}-\underbrace{\frac{\sigma(1-\sigma)}{2} \operatorname{Var}\left(\frac{\theta_{i t}}{\theta_{t}}\right)}_{\text {Dispersion }})
\end{aligned}
$$


with

$$
\left\{\begin{array}{l}
\mu_{t}^{s}=\sigma \sum_{i, j} \frac{U_{j i t}}{U_{t}}\left(s_{j i t}-1\right) \\
\mu_{t}^{m}=\sum_{i} \frac{U_{i t}}{U_{t}}\left(\frac{\mu_{i}}{\mu_{0}}-1\right) \\
\operatorname{Var}\left(\frac{\theta_{i t}}{\theta_{t}}\right)=\sum_{i} \frac{U_{i t}}{U_{t}}\left(\frac{\theta_{i t}}{\theta_{t}}-1\right)^{2}
\end{array}\right.
$$

where the second order terms in $\mu_{t}^{s}$ and $\mu_{t}^{m}$ as well as the cross-order terms have been omitted for clarity of exposition, since they are in practice negligible.

Finally, using our specification to capture the effect of workers' characteristics on search efficiency

$$
s_{j i t}=e^{\beta X_{j i t}}
$$

with $X_{j i t}=\left[1, x_{j i t}^{1}, . ., x_{j i t}^{K}\right]$ a vector of worker characteristics for type $j$ in segment $i$ at time $t$ and $\beta=\left[\beta_{0}, \ldots, \beta_{K}\right]$ the corresponding vector of coefficients, we can decompose the composition effect as follows

$$
\mu_{t}^{s}=\sigma \sum_{i, j} \frac{U_{j i t}}{U_{t}} \sum_{k=0}^{K} \beta_{k}\left(x_{j i t}^{k}-\bar{x}^{k}\right)
$$

with $\bar{x}^{k}=\frac{1}{T} \sum_{t=1}^{T} \sum_{i, j} \frac{U_{i j t}}{U_{t}} x_{i j t}^{k}$.

\section{Robustness check: time-varying duration dependence}

While we imposed the effect of duration on an individual's job finding probability to be constant over time, recent research has shown that the effect of duration may actually vary over the cycle, leading us to possibly overestimate the contribution of duration in the Great Recession. Kroft, Lange and Notowidiglo (2013) found that the effect of duration on the job finding rate is weaker in more depressed labor markets. By not allowing for the strength of duration dependence (the slope of the duration dependence relationship) to vary over the business cycle, we could be overstating the contribution of duration to the decline in matching efficiency. Thus, one could worry that the large contribution of duration to the recent decline in aggregate matching efficiency (partly responsible for the break-down of the standard matching function) is overstated, because we did not allow the strength of duration dependence to vary over the business cycle (and become weaker during the Great Recession).

To evaluate whether the strength of duration dependence varied before and after 2008, we estimated the effect of worker characteristics (the parameter vector $\beta$ ) on job finding probability using either pre- or post-2008 data and compare the two sets of estimated parameters. Figure 10 presents the difference between the 2008-2012 coefficients and the 1994-2007 coefficients 
(expressed in units of job finding rate) and shows that this worry is not warranted. Looking at the change in the estimated coefficients post-08, we can see that the effect of duration on an individual's job finding rate was actually stronger, not weaker, during the last recession. ${ }^{35} \mathrm{As}$ a result, the contribution of duration to the recent decline in matching efficiency could actually be even stronger, not weaker, than reported in Section 5.

\footnotetext{
${ }^{35}$ Interestingly, this finding runs counter to Kroft et al. (2013), who find that duration dependence is weaker in depressed labor markets, and thus suggests that mechanisms other than screening (for instance ranking, see Kroft et al., 2013) contribute to the duration dependence.
} 

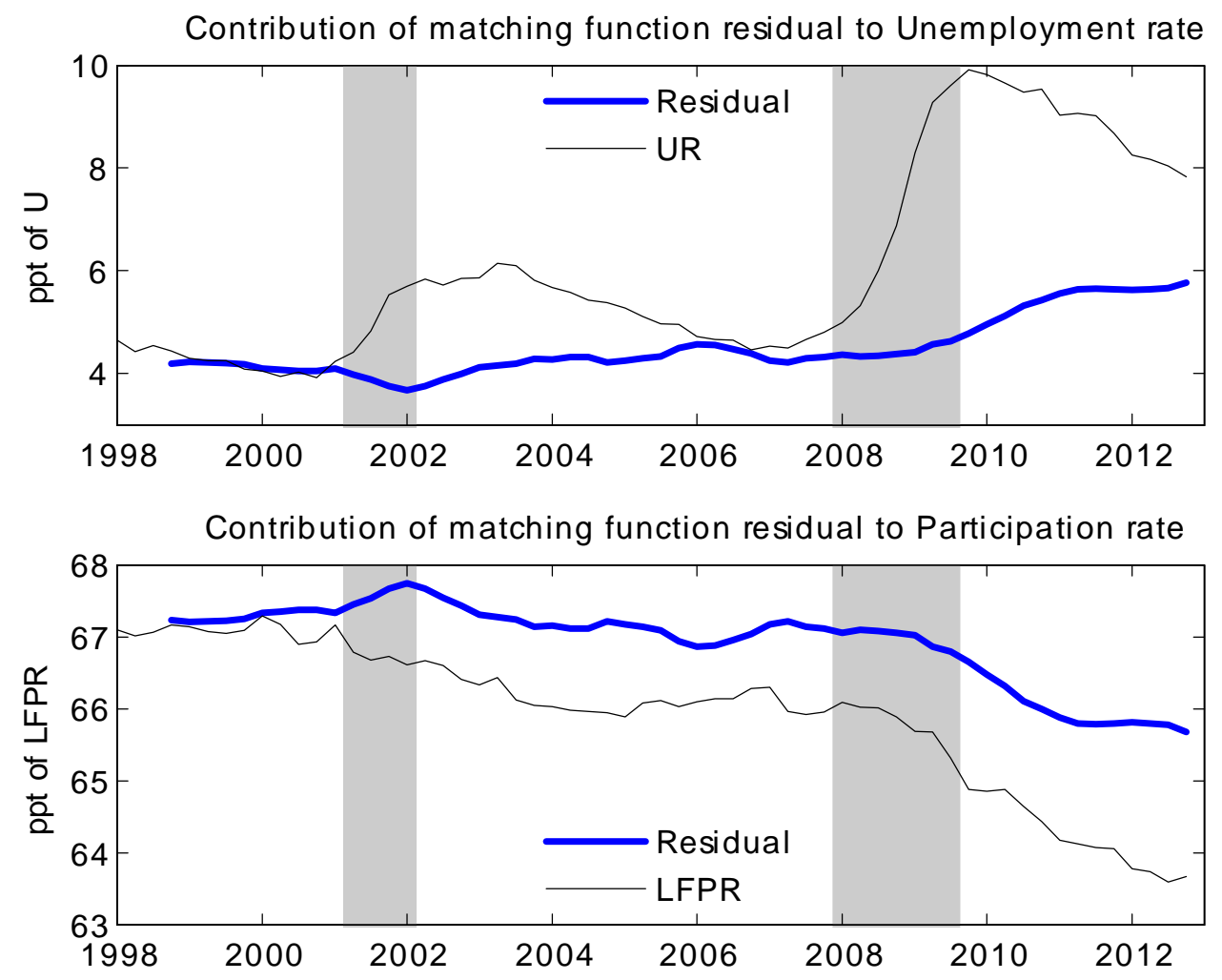

Figure 1: Unexplained movements in the aggregate job finding rate (Residual from a standard matching function regression) in units of unemployment rate and labor force participation rate, along with the unemployment (UR) and participation (LFPR) rates, 1998-2012. For clarity of exposition, the level of the residuals in both panels is set arbitrarily to equal the 1999Q1 level of, respectively, unemployment and participation. The plotted series are 4-quarter moving averages. Grey bars indicate NBER recession dates. 

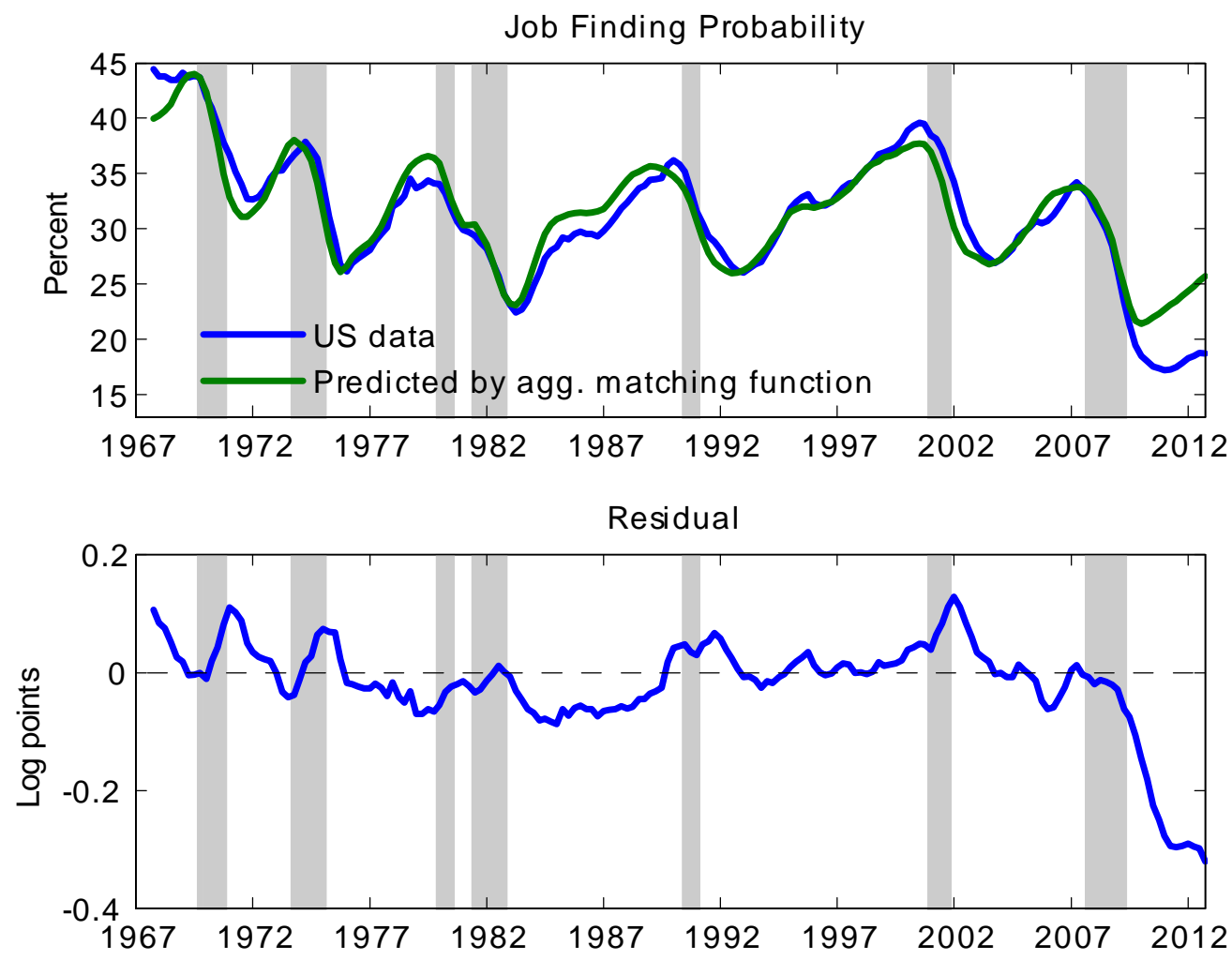

Figure 2: Empirical job finding rate, job finding rate predicted by an aggregate matching function and $(\log )$ residual, the (log) difference between the empirical and the predicted job finding rate, 1968-2012. The plotted series are the 4-quarter moving average. Grey bars indicate NBER recession dates. 

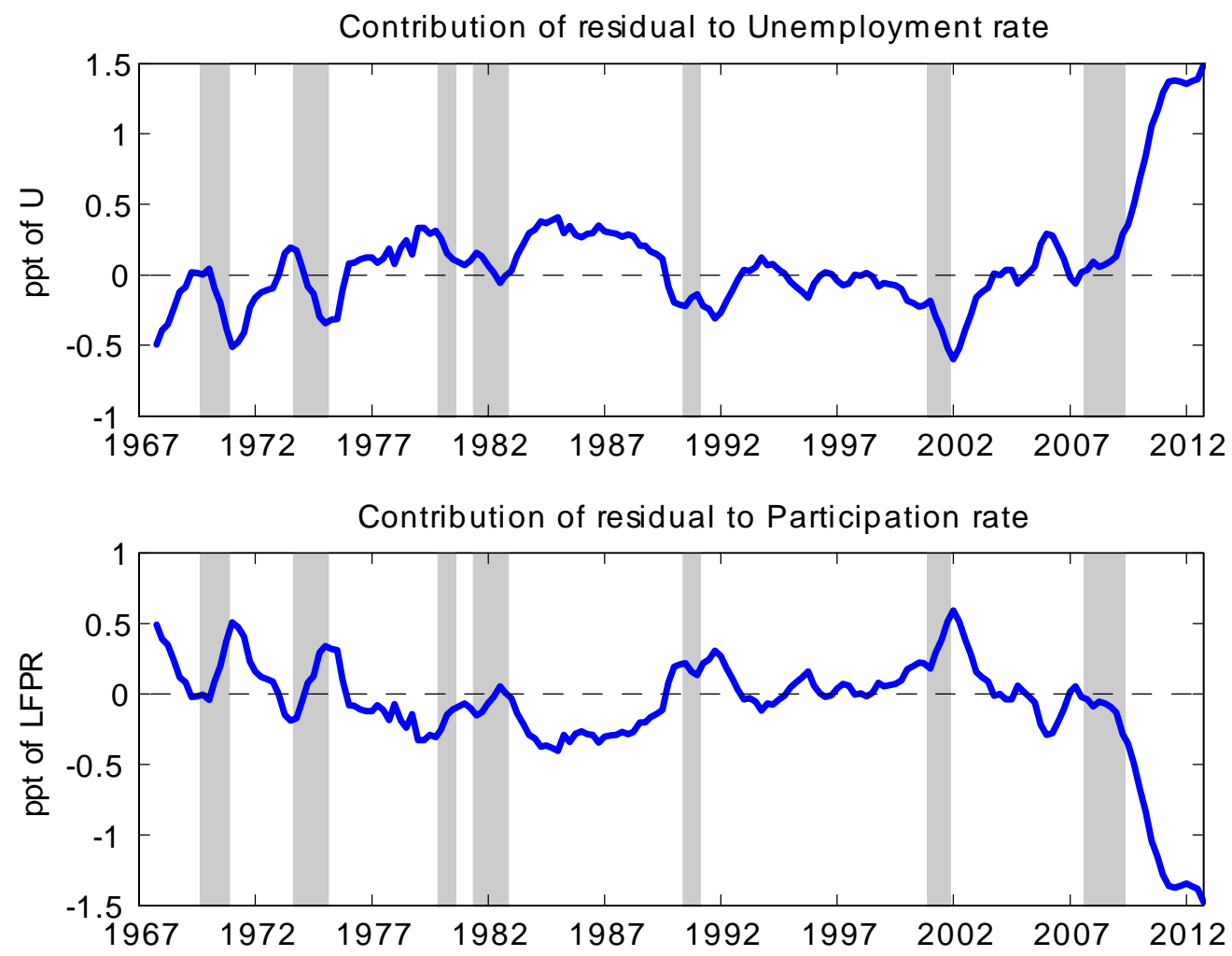

Figure 3: Unexplained movements in the aggregate job finding rate in units of unemployment rate and labor force participation rate, 1968-2012. The plotted series are 4-quarter moving averages. Grey bars indicate NBER recession dates. 

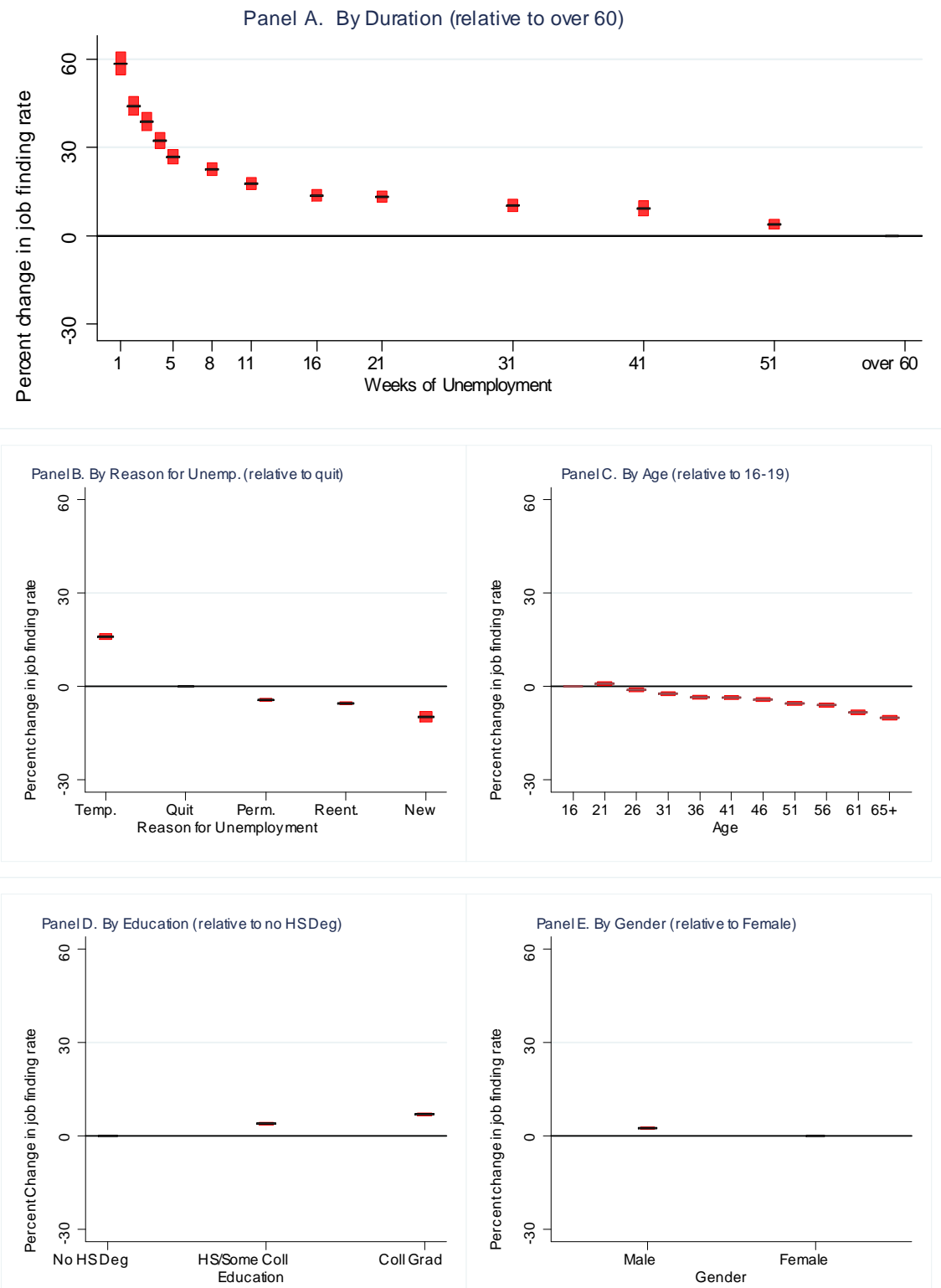

Figure 4: Coefficient estimates, 1994-2007. The black bars denote the point estimates and the red bars denote \pm 2 standard-errors. 


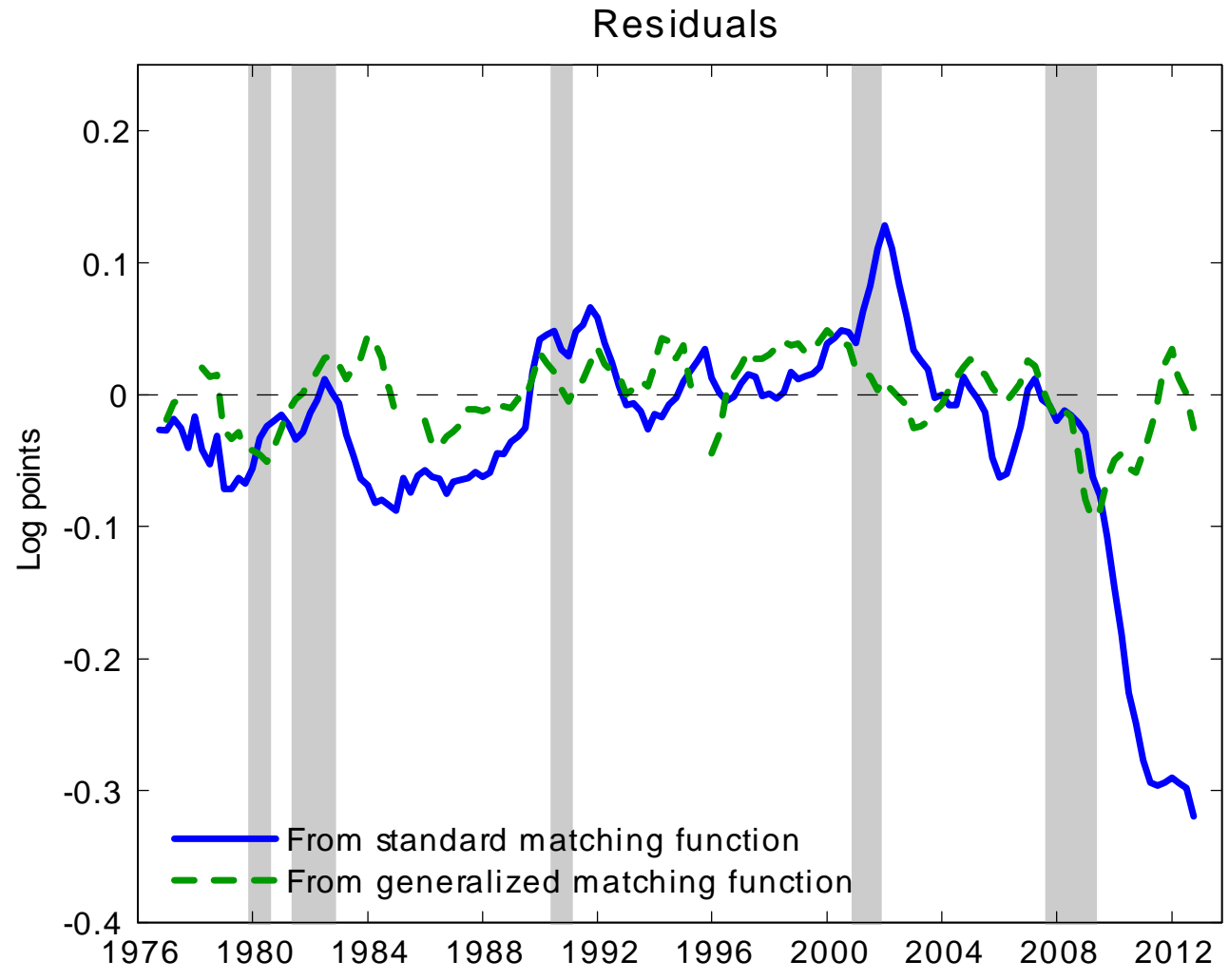

Figure 5: Unexplained movements in the aggregate job finding rate. Residuals obtained from regressions estimated over 1976-2007. All series are 4-quarter moving averages. Grey bars indicate NBER recession dates. 

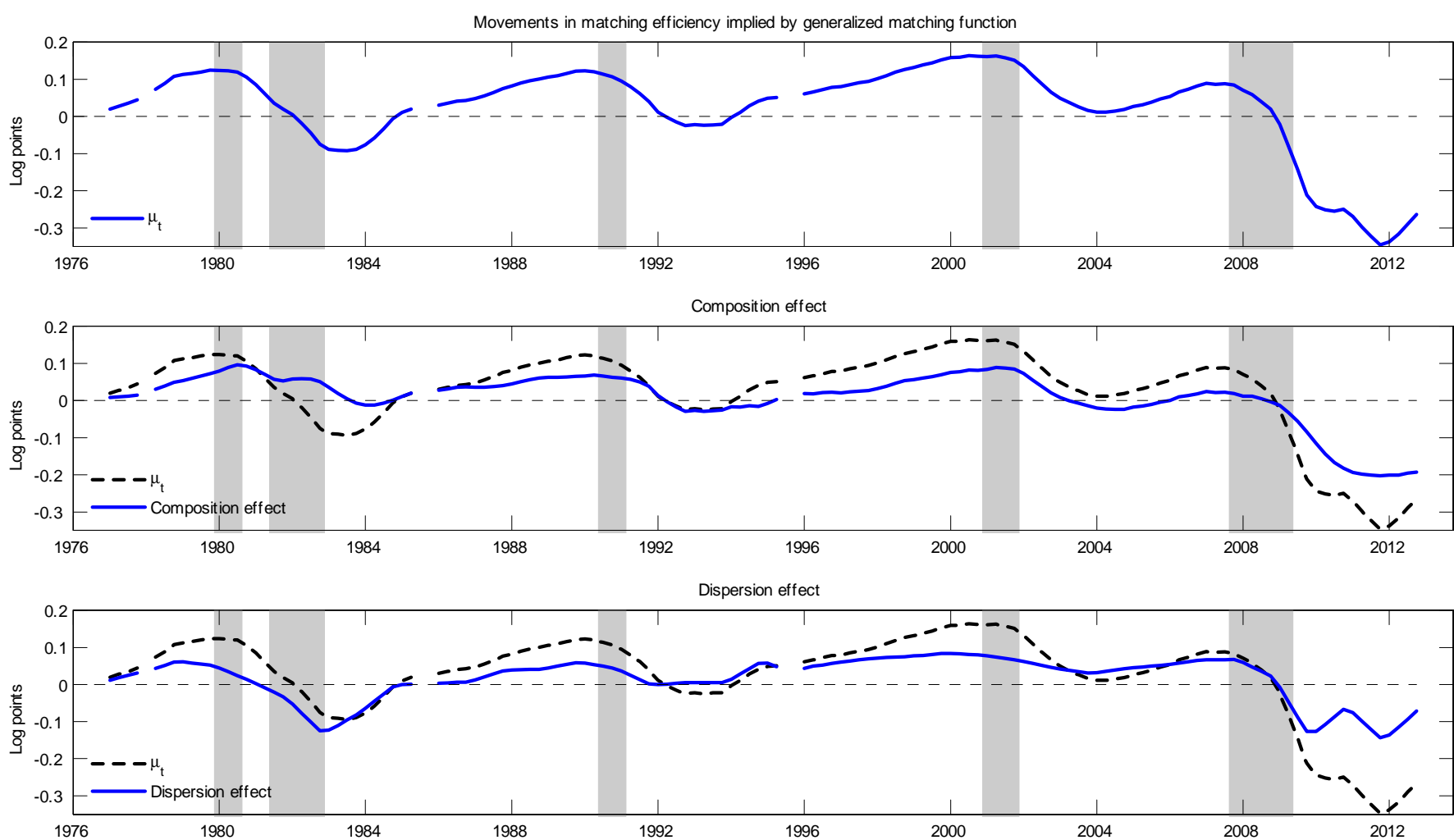

Figure 6: Decomposition of movements in aggregate matching efficiency. Upper panel: movements in aggregate matching efficiency, $\mu_{t}$, implied by the generalized matching function. Middle panel: movements in $\mu_{t}$ due to composition effect. Lower panel: movements in $\mu_{t}$ due to dispersion effect. All series are 4-quarter moving averages. Grey bars indicate NBER recession dates. 


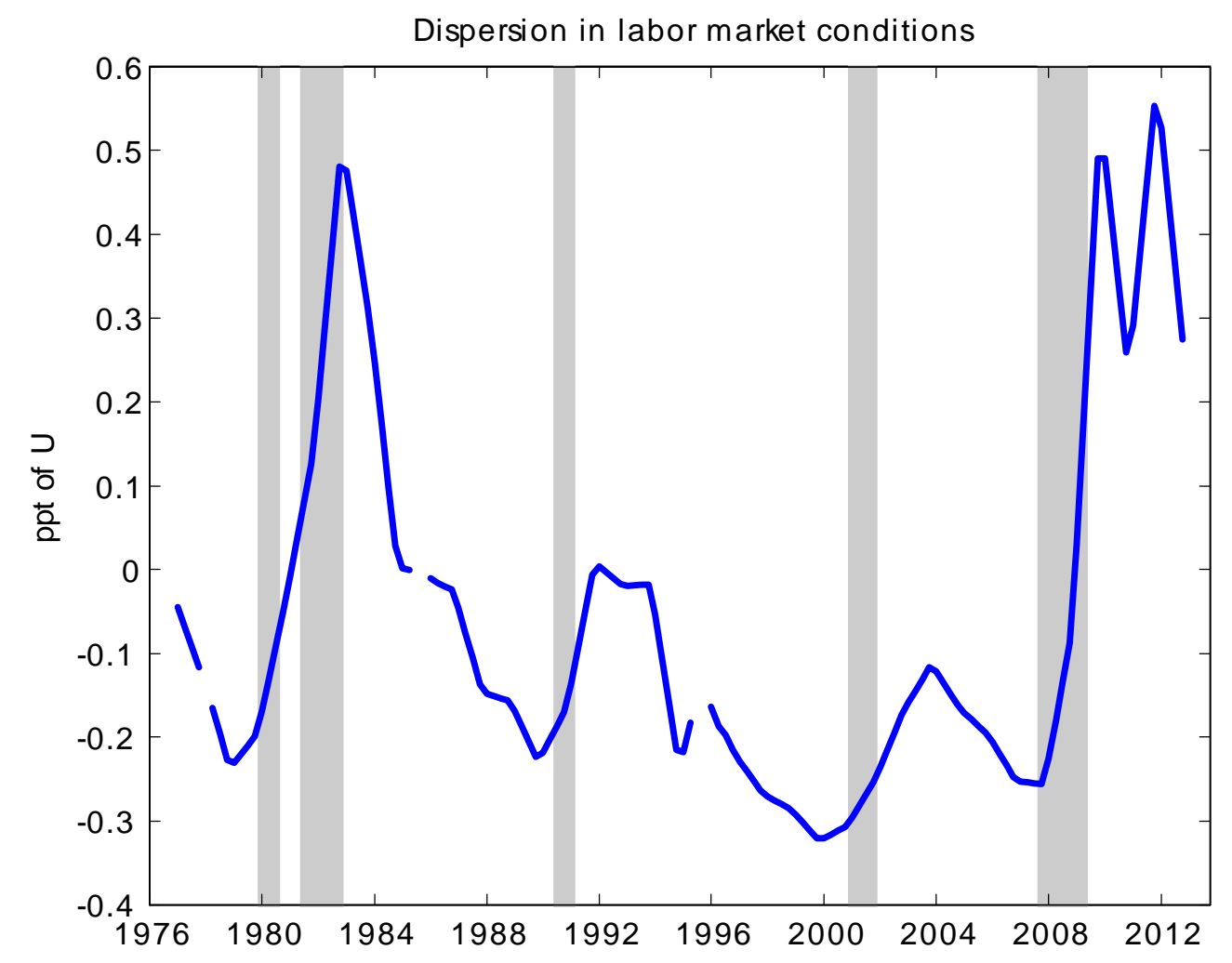

Figure 7: Dispersion in labor market conditions (expressed in percentage points of unemployment, see appendix), 1976-2012. 4-quarter moving averages. Grey bars indicate NBER recession dates. 

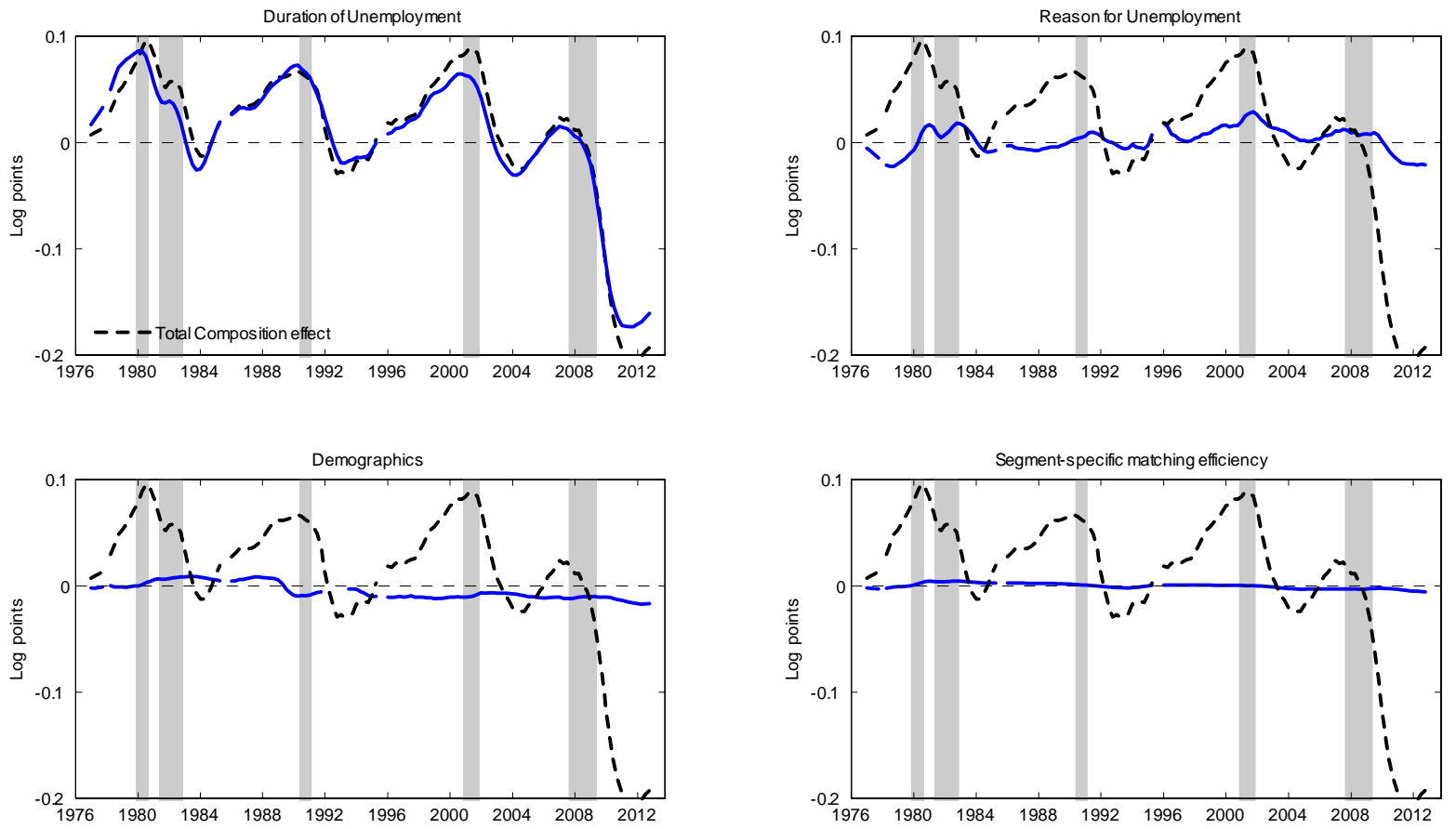

Figure 8: Decomposition of the composition effect into the contributions of unemployment duration, reason for unemployment, demographics (age, sex and education), and segmentspecific matching efficiency. The dashed line plots the total composition effect. The results were obtained from a regression estimated over 1976-2007. All series are 4-quarter moving averages. Grey bars indicate NBER recession dates. 

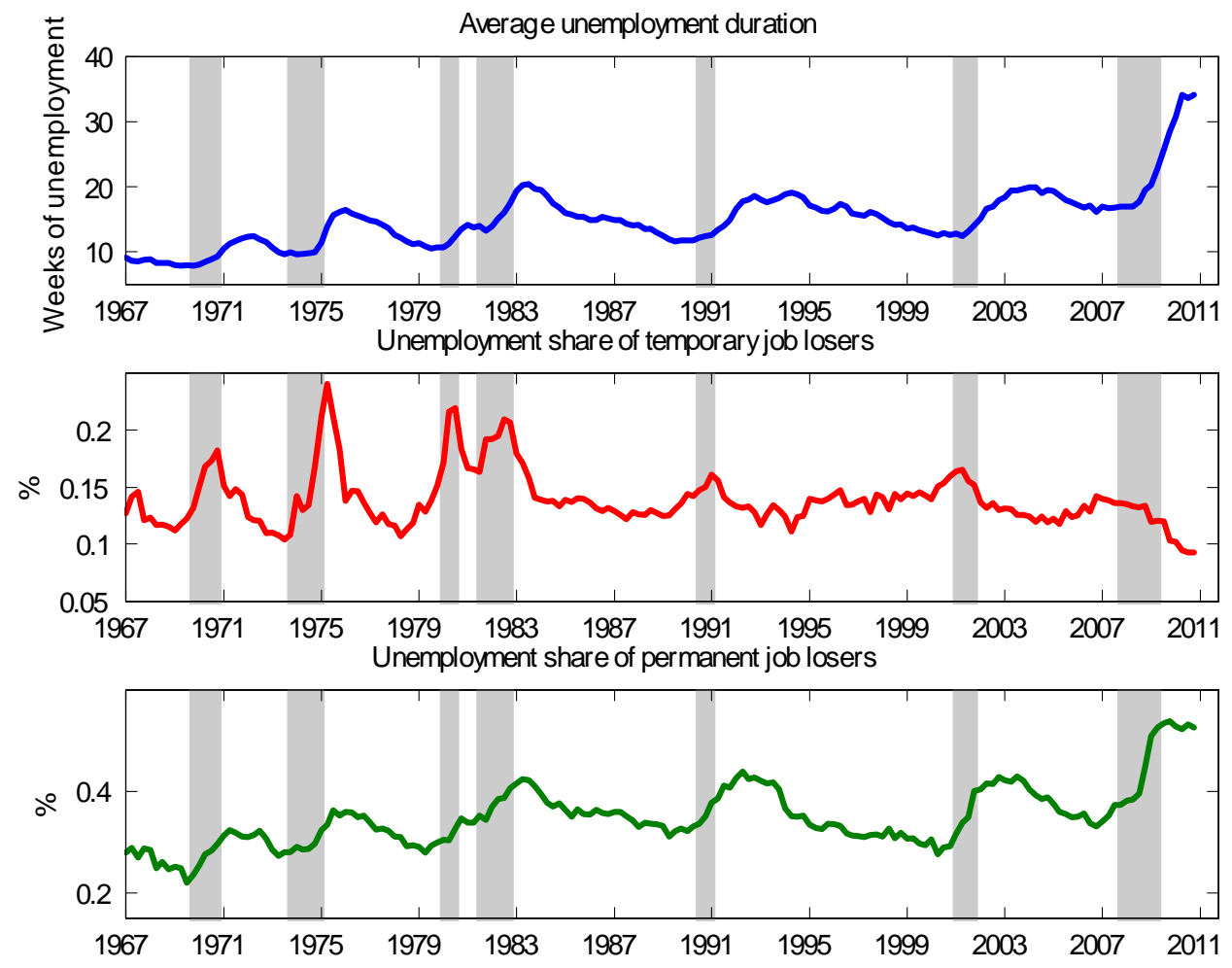

Figure 9: Average unemployment duration in weeks (upper-panel), share of job losers on temporary layoffs (middle-panel) and share of job losers on permanent layoffs (lower-panel). 1967-2010. 

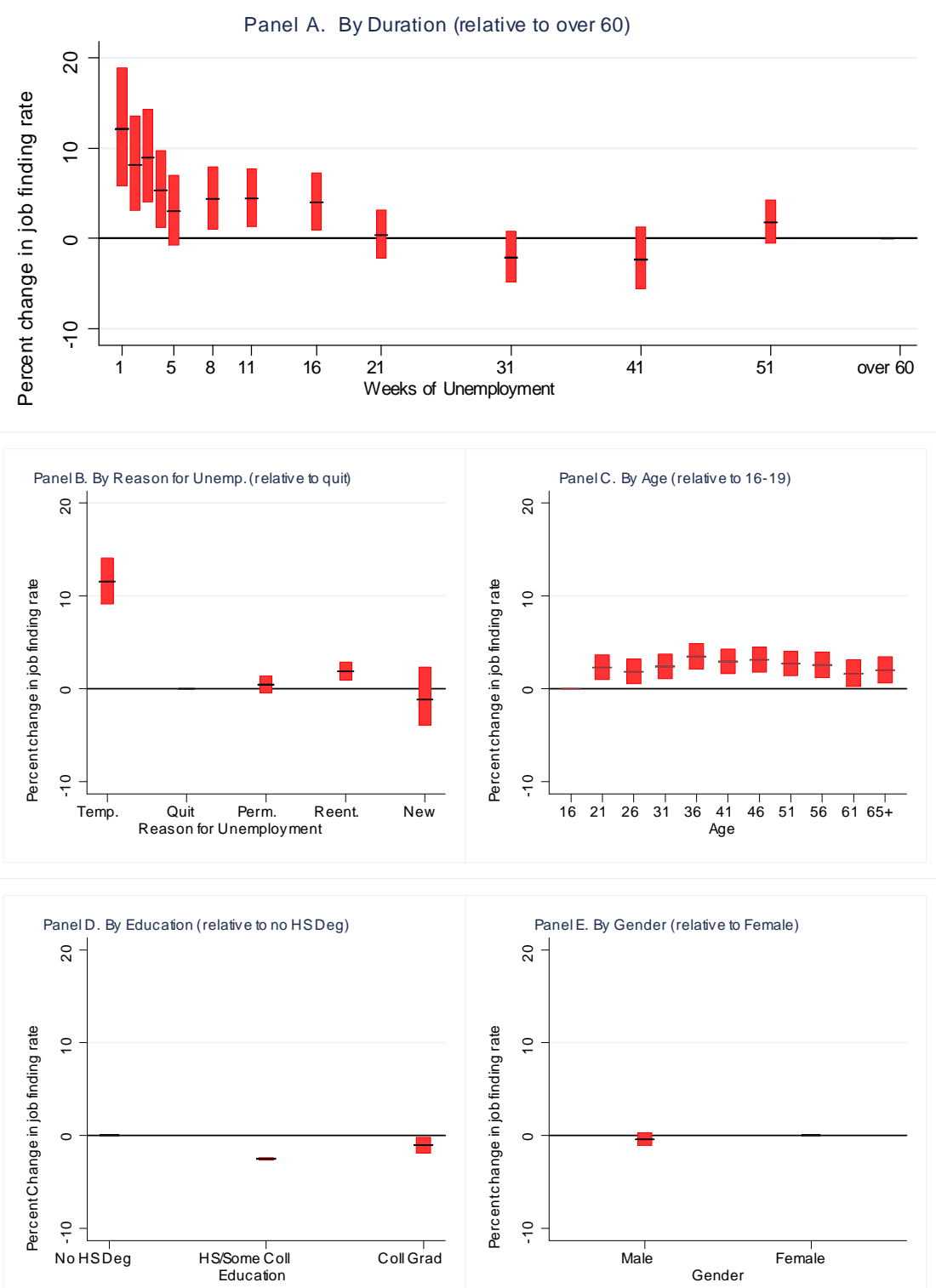

Figure 10: Difference between the coefficients estimated over 2008-2012 and the coefficients estimated over 1994-2007. The black bars denote the point estimates and the red bars denote \pm 2 standard-errors. 
Table 1: Estimates of the matching function elasticity

\begin{tabular}{|c|c|c|c|}
\hline Dependent variable: & $f_{t}$ & $f_{t}$ & $F_{j i t}$ \\
\hline $\begin{array}{l}\text { Sample } \\
\text { (quarterly frequency) }\end{array}$ & $1968-2007$ & 1968-2007 & 1976-2007 \\
\hline Regression & (1) & (2) & (3) \\
\hline Estimation & OLS & GMM & $\mathrm{BF}$ \\
\hline $1-\sigma$ & $\begin{array}{c}0.33^{* * *} \\
(0.01)\end{array}$ & $\begin{array}{c}0.34 * * * \\
(0.01)\end{array}$ & $\begin{array}{c}0.18^{* * *} \\
(0.02)\end{array}$ \\
\hline Endog. mvts in $\mu_{\mathrm{t}}$ & No & No & Yes \\
\hline $\mathrm{R}^{2}, 1976-2012$ & 0.78 & -- & 0.88 \\
\hline
\end{tabular}

